\title{
LAS NUEVAS REGLAS SOBRE INFORMACIÓN Y PRUEBA DEL DEREGHO EXTRANJERO EN EL SISTEMA ESPAÑOL DE DERECHO INTERNACIONAL PRIVADO*
}

\author{
NEW RULES CONCERNING INFORMATION AND PROOF \\ OF FOREIGN LAW IN THE SPANISH PRIVATE INTERNATIONAL \\ LAW SYSTEM
}

\author{
Alfonso YBARRA BORES** \\ Andrés RODRÍGUEZ BENOT***
}

RESUMEN: La entrada en vigor en España de la Ley 29/2015, 30 de julio, de cooperación jurídica internacional en materia civil, ha supuesto la incorporación de reglas especiales acerca de la información y prueba del derecho extranjero. Reglas que, por una parte, ofrecen soluciones novedosas en este campo y que, por otra, adolecen de ausencia de una reforma global de este sector del derecho internacional privado.

Palabras clave: Cooperación internacional, subsidiariedad, información y prueba sobre el derecho extranjero.
ABSTRACT: The entry into force in Spain of the 29/2015 (30 $0^{\text {th }}$ fuly) Act concerning the international legal cooperation in civil matters has added special rules concerning the information and proof of foreign law. On the one hand those rules offer innovative solutions in this field. On the other hand they are characterized by the absence of a comprehensive reform of this segment of private international law.

Keywords: International cooperation, subsidiarity, information and proof of foreign law.

* Trabajo elaborado en el marco del Proyecto de I+D+i DER2014-58581-R, del Programa Estatal de Investigación, Desarrollo e Innovación orientada a los retos de la sociedad del ministerio de economía y competitividad.

** Profesor titular (AC) de derecho internacional privado, Universidad Pablo de Olavide, Sevilla.

*** Catedrático de derecho internacional privado, Universidad Pablo de Olavide, Sevilla.

Boletín Mexicano de Derecho Comparado, nueva serie, año XLIX, núm. 150, septiembre-diciembre de 2017, pp. 1351-1394

Esta obra está bajo una Licencia Creative Commons Atribución-NoComercial-SinDerivar 4.0 Internacional, IIJ-UNAM. 
Esta revista forma parte del acervo de la Biblioteca Jurídica Virtual del Instituto de Investigaciones Jurídicas de la UNAM

SUMARIO: I. Introducción. II. La información acerca del derecho extranjero. III. La prueba del derecho extranjero por las autoridades españolas.

\section{INTRODUCGIÓN}

El incremento del tráfico jurídico externo es una realidad creciente e innegable en la sociedad globalizada en que vivimos. A fin de abordarlo técnicamente, los mecanismos de fuente interna de que dispone el sistema español de derecho internacional privado resultan en gran medida heterogéneos, inadecuados y desfasados. Atento a ello, el legislador dispuso, con ocasión de la aprobación de la Ley 1/2000, 7 de enero, de enjuiciamiento civil, la necesidad de que el gobierno presentara en las cortes generales en el plazo de seis meses un proyecto de ley de cooperación jurídica internacional en materia civil. ${ }^{1}$ Tras alguna iniciativa, esencialmente de orden doctrinal, ${ }^{2}$ fue catorce años después cuando un grupo de expertos designado por el Ministerio de Justicia, con la participación de todas las instituciones públicas implicadas, elaboró una propuesta de borrador de anteproyecto, que desembocó finalmente en la promulgación de la Ley 29/2015, 30 de julio, de cooperación jurídica internacional en materia civil (en lo sucesivo LCJIMC), en vigor desde el 20 de agosto de 2015. ${ }^{3}$

1 En realidad, la necesidad de una ley de esta índole se puso ya de manifiesto desde la promulgación de la Ley Orgánica 6/1985, de 1 de julio, del Poder Judicial. En 1997 se elaboró un primer anteproyecto de Ley de cooperación jurídica internacional en materia civil que, aunque dictaminado por el Consejo de Estado el 4 de diciembre de dicho año, no continuó tramitándose.

2 Se trata de sendos textos elaborados en el área de derecho internacional privado de la Universidad Autónoma de Madrid en 2001 y 2012; esta última rubricada "Una propuesta de Ley de cooperación jurídica internacional en materia civil", en Virgós Soriano, Miguel et al., Boletín de Información del Ministerio de Justicia, núm. 2143, junio de 2012, pp. 1-47, disponible en: http://web.ua.es/es/fedip/documentos/textobimjpropuesta20ley20cooperacion20juridica-20internacional.pdf Sobre ello véanse, asimismo, Heredia Cervantes, Iván y Rodríguez Pineau, Elena, "Algunas propuestas para una futura ley de cooperación jurídica internacional en materia civil", Revista Furídica Universidad Autónoma de Madrid, núm. 28, 2013, pp. 91-106.

3 Boletín Oficial del Estado núm. 182, del 31 de julio de 2015. El texto del anteproyecto de Ley aprobado por el gobierno el 4 de julio de 2014 puede verse en: http://wrere.mjusticia.gob. es $/$ cs $/$ Satellite $/$ Portal $/ 1292427070261$ ? blobheader=application $\% 2$ FpdfËblobheadername $1=$ Conte ntDisposition Eblobheadername $2=$ Medios Eblobheadervalue $1=$ attachment $\% 3 B+$ filename $\% 3 D A P L$ Coop_fur\%C3\%ADdica_Internal_Textopdf\&blobheadervalue2 $=1288788905837$; sobre él

Esta obra está bajo una Licencia Creative Commons

Atribución-NoComercial-SinDerivar 4.0 Internacional, IIJ-UNAM.

Boletín Mexicano de Derecho Comparado, núm. 150, pp. 1351-1394 
Se trata de una Ley que nace - en palabras de su preámbulo - con el ánimo de aportar seguridad jurídica y certidumbre añadida a este sector, lo que se proyecta sobre un concepto amplio de cooperación jurídica internacional, pues la finalidad de la norma es entendida lato sensu dado que pretende disciplinar no sólo los sectores tradicionalmente incluidos en la cooperación jurídica internacional, sino que va más allá; así, la LGJIMC aborda materias como la litispendencia y la conexidad internacionales, el reconocimiento y ejecución de sentencias o la información y prueba del derecho extranjero. Es precisamente este último aspecto lo que atrae nuestra atención y configura el objeto de este opúsculo; a tal fin, conforme a un iter lógico que exige invertir el orden sistemático de los títulos II y III de la Ley (artículos 33 a 36), analizaremos en primer término la infor-

pueden consultarse el Dictamen 236/2015 del Consejo de Estado, 26 de marzo, disponible en: http://wrweboe.es/buscar/doc.php?id =CE-D-2015-236, el informe del Consejo Fiscal del 20 de septiembre de 2014, disponible en: https://wrwe.fiscal.es/fiscal/PA_WebApp_SGNTJ_NFIS/descarga/25_09_2014_Informe_CF_Cooperacion_jur\%C3\%ADdica_Internacional_materia_civil:idFile $=c e 5 b b 0 d 38 f 5 c-4 a 1 c-8 c d a-28 d 6 c e a 4 c c d e$ y el del Consejo General del Poder Judicial del 30 de septiembre de 2014, disponible en: http://wrwe.poderjudicial.es/cgpj/es/ Poder-Fudicial/ConsejoGeneraldelPoderfudicial/ActividaddelCGPJ/Informes/InformealAnteproyectodeLey-de-cooperacion-juridica-internacional-en-materia-civil. Emitieron, asimismo, sendos informes respecto al anteproyecto el Ministerio de Asuntos Exteriores y Cooperación (29 de julio de 2014), el Consejo General de Procuradores de España (18 de noviembre de 2014), el Colegio de Registradores de la Propiedad y Mercantiles de España (18 de noviembre de 2014), el Colegio de Abogados de Madrid (25 de noviembre de 2014) y el Consejo General del Notariado (3 de diciembre de 2014).

Unos primerísimos comentarios acerca de la ley pueden verse en algunos blogs, como los de Carballo Piñeiro, Laura, "España: la ley de cooperación jurídica internacional en materia civil", disponible en: https://cartasblogatorias.com/2015/11/26/1003/; Garau Sobrino, Federico, disponible en: http://conflictuslegum.blogspot.com.es/2015/07/boe-de-3172015.html; y Miguel Asensio, Pedro, disponible en: http://pedrodemiguelasensio.blogspot.com.es/2015/08/ comentariolaley292015decooperacion.html. De igual forma, véase Arroyo, Elvira, "Primera ley española de cooperación jurídica internacional civil”, Escritura Pública, núm. 94, julio-agosto de 2015, pp. 28-31, disponible en: http://wwrenotariado.org/liferay/c/document_library/ get_file:folderId=12092 Ename=DFE-142510.pdf; Bonillo Garrido, Luis, "Comentarios relativos al Anteproyecto de ley de cooperación jurídica internacional”, Diario La Ley, núm. 8486, 23 de febrero de 2015; Rodríguez Benot, Andrés, "La ley de cooperación jurídica internacional en materia civil", Cuadernos de Derecho Transnacional, vol. 8, núm. 1, 2016, pp. 234-259; y Vaquero López, María del Carmen, "Nuevas normas de derecho internacional privado estatal: una primera aproximación a las reformas legislativas de julio de 2015", Revista Aranzadi Doctrinal, núm. 9, 2015, pp. 197-222, especialmente pp. $216-221$.

Esta obra está bajo una Licencia Creative Commons Atribución-NoComercial-SinDerivar 4.0 Internacional, IIJ-UNAM. Boletín Mexicano de Derecho Comparado, núm. 150, pp. 1351-1394 
Esta revista forma parte del acervo de la Biblioteca Jurídica Virtual del Instituto de Investigaciones Jurídicas de la UNAM

mación sobre un ordenamiento extranjero (epígrafe II) y seguidamente la prueba del mismo (epígrafe III).

\section{LA INFORMACIÓN AGERCA DEL DEREGHO EXTRANJERO}

El título III de la LCJIMC, "De la información del derecho extranjero", está integrado por tres artículos: el 34 "De la información jurídica", el 35 "De las solicitudes de información del derecho extranjero" y el 36 "De las solicitudes de información del derecho español". ${ }^{4}$

El primero de estos preceptos dispone que la solicitud de la información sobre un ordenamiento extranjero podrá referirse "al texto, vigencia y contenido de la legislación, a su sentido y alcance, a la jurisprudencia, al marco procedimental y de la organización judicial, y a cualquier otra información jurídica relevante". ${ }^{5}$ Como se puede apreciar, se efectúa una relación detallada de los distintos aspectos que pueden ser objeto de la información de un derecho extraño a quien la solicita. Se trata de un elenco que da lugar a que nos encontremos ante un concepto amplio o abierto del posible objeto de la información acerca del tal derecho, regulándose acto seguido en los artículos 35 y 36, respectivamente, cómo deben tramitarse las solicitudes de información sobre tales aspectos tanto ad extra (información activa del derecho extranjero) como ad intra (información pasiva del derecho español). ${ }^{6}$

4 La rúbrica del citado título resulta parcial o insuficiente, pues no responde a las dos realidades que disciplinan los artículos 35 y 36 , sino sólo a la primera de ellas.

$5 \mathrm{Al}$ igual que la rúbrica del título III, la de este artículo es igualmente parcial o insuficiente, ya que al tratarse de una noma común a modo de antesala de los artículos 35 y 36, debería referirse a la información sobre el derecho extranjero (perspectiva activa) o acerca del derecho español (óptica pasiva) y no únicamente del primero.

6 Lo cierto es que el resultado alcanzado con esta regulación no parece el más adecuado, al menos desde el punto de vista formal o sistemático. En primer término, porque el artículo 34 podría bastar para disciplinar a qué puede referirse la información sobre un derecho extraño, sin necesidad de reiterarlo en los artículos 35 y 36 (infra). En segundo lugar, porque la relación de documentos descrita en el artículo 34 parece revelar la confusión del legislador entre la información de un ordenamiento extranjero y su prueba, pues tal relación - al menos buena parte de ella - lo es más bien de medios para acreditar el contenido y la vigencia del derecho extranjero, por lo que debería estar ubicada en el artículo 33 (infra).

Esta obra está bajo una Licencia Creative Commons

Atribución-NoComercial-SinDerivar 4.0 Internacional, IIJ-UNAM.

Boletín Mexicano de Derecho Comparado, núm. 150, pp. 1351-1394 
Por su parte, el artículo 34 consagra un amplio abanico de materias como posible objeto de información, a saber:

1. En primer término, el "texto, vigencia y contenido de la legislación”, expresión que identificamos con la teoría exhaustiva en torno al objeto de la prueba del derecho extranjero que abordamos en el epígrafe III (infra).

2. En segundo lugar cabe, asimismo, solicitar información "del marco procedimental y de la organización judicial" de un Estado. Se trataría ahora de recabar información sobre aspectos adjetivos relacionados con tales ámbitos, dado que en algún caso ello puede tener interés para las autoridades de un país a la hora de aplicar el derecho de otro. Sería como muestra el caso en que se interesara conocer el tipo de procedimiento en el cual se hubiera dictado una resolución de interés para la correcta resolución del caso; por ejemplo, a efectos de constatar el rango o categoría de la autoridad que la dictó en el extranjero o la configuración del procedimiento a efecto de su fiabilidad.

3. Por último, se contempla a modo de norma de cierre, la posibilidad de solicitar "cualquier otra información jurídica relevante". Se trata con ello de dejar abierta la posibilidad de demandar otras informaciones que se consideren trascendentes para que, en caso de mantener todavía la autoridad estatal de que se trate alguna duda sobre el derecho de otro país y su aplicación al caso concreto, pueda finalmente aplicarlo sin que le suscite "la menor duda razonable".

Los dos artículos restantes del título III (el 35 y el 36) abordan la cuestión de la información de un derecho extraño para la autoridad que la pretende, si bien desde distinta óptica: en el primer caso cuando es la autoridad española la que desea informarse sobre un ordenamiento extranjero (solicitud ad extra o activa), y en el segundo cuando es una autoridad extranjera la que persigue ilustrarse acerca del derecho español (solicitud ad intra o pasiva). Por la elevada coincidencia de sus contenidos, estudiaremos la cuestión haciendo referencia diferenciada a ambos supuestos cuando así proceda; para ello distinguiremos las cuestiones relativas al mecanismo propiamente dicho de la solicitud de información sobre un derecho 
foráneo (epígrafe 2), a las autoridades intervinientes en él (epígrafe 3), al contenido de la solicitud (epígrafe 4), al objeto de ésta (epígrafe 5) y a la financiación de la misma (epígrafe 6). Al análisis práctico de ellas atiende la estructura siguiente, que precederemos del tratamiento del carácter subsidiario de estas normas (epígrafe 1).

\section{El carácter subsidiario de los mecanismos de información de los artículos 35 y 36 de la LCFIMC respecto de otros mecanismos}

Los mecanismos dispuestos en los artículos 35 y 36 resultan doblemente subsidiarios respecto de otros, a saber: la regulación de fuente supraestatal o interna de naturaleza especial por una parte (apartado A) y el uso de la técnica de la comunicación judicial directa por otra (apartado B).

\section{A. Los mecanismos de fuente supraestatal o interna de fuente especial} para obtener información sobre un derecho extranjero

Exartículo 2o. de la LCJIMC, los mecanismos de sus artículos 35 y 36 sólo se utilizarían de no existir ora un instrumento de fuente supraestatal (apartado $a$ ), ora otras normas de origen interno de naturaleza especial que regularan esta materia (apartado b); y ello por cuanto en cualquiera de ellos se podrían contener soluciones ad hoc que respondieran al principio de especialidad en este ámbito. ${ }^{7}$

\section{a. Los mecanismos de fuente supraestatal para obtener información sobre un derecho extranjero}

En lo que se refiere a los instrumentos supraestatales en que cabe hallar una regulación para la obtención de información acerca de un ordenamiento extraño, hemos de distinguir entre los de la Unión Europea 1) y los de naturaleza convencional 2).

7 Rodríguez Benot, Andrés, "La ley de cooperación jurídica internacional en materia civil...", cit., pp. 236 y 237. Pretende plausiblemente el legislador con este carácter aportar seguridad jurídica y certidumbre a un sistema que adolece en buena medida de heterogeneidad y complejidad para el aplicador del derecho y, no digamos, para el justiciable.

Esta obra está bajo una Licencia Creative Commons

Atribución-NoComercial-SinDerivar 4.0 Internacional, IIJ-UNAM.

Boletín Mexicano de Derecho Comparado, núm. 150, pp. 1351-1394 
1) No existe en la Unión Europea un instrumento normativo propiamente dicho para la información sobre el derecho de los Estados miembros $;^{8}$ de lo que disponen las autoridades de éstos es del mecanismo ofrecido por la red judicial europea en materia civil y mercantil, creada por la Decisión 2001/470/CE del Consejo, de 28 de mayo de 2001, y cuyo funcionamiento se llevó el 1 de diciembre de $2002 .{ }^{9}$ A través de esta vía cabe solicitar información sobre ordenamientos de Estados miembros (en materia civil, mercantil, laboral o procesal) a las autoridades o puntos de contacto nacionales responsables de prestar asistencia a los órganos jurisdiccionales locales con el objetivo final de promover la cooperación judicial y legal entre tales Estados. Vinculada a esta Red es de destacar, como instrumento útil para obtención de información, el Atlas Judicial Europeo en materia civil y mercantil. ${ }^{10}$

8 Respecto de otra área geográfica es de reseñar, de igual modo, la existencia de la Red Iberoamericana de Cooperación Jurídica Internacional (https://wwew.iberred.org/); creada en 2004, es una estructura formada por puntos de contacto procedentes de los ministerios de justicia y autoridades centrales, fiscalías y ministerios públicos, y poderes judiciales de los veintitrés países que componen la Comunidad Iberoamericana de Naciones, orientada a la optimización de los instrumentos de asistencia judicial civil y penal, y al reforzamiento de los lazos de cooperación entre nuestros países constituyendo así un paso fundamental en la conformación de un espacio judicial iberoamericano (entendido como un escenario específico donde la actividad de cooperación judicial sea objeto de mecanismos reforzados, dinámicas e instrumentos de simplificación y agilización, en la consecución de un tutela judicial efectiva).

9 La base jurídica de esta norma se modificó en 2009, disponible en: http://eur-lex. europa.eu/legalcontent/ES/TXT/HTML/?uri=CELEX:02001D047020110101 ङfrom=ES; en la fecha de elaboración de estas líneas, todos los Estados miembros salvo Dinamarca participaban en la Red. A la misma cabe acceder a través de la web del Portal Europeo de eJusticia en: https://e-justice.europa.eu/. Véanse Escalada López, María Luisa, "Instrumentos orgánicos de cooperación judicial: magistrados de enlace, red judicial europea y Eurojust", en Jimeno Bulnes, Mar (coord.), La cooperación judicial civil y penal en el ámbito de la Unión Europea: instrumentos procesales, Barcelona, Bosch, 2007, pp. 95-121; Garriga Suau, Georgina, "La creciente potencialidad de la red judicial europea en materia civil y mercantil en la construcción del espacio judicial europeo", Anuario Español de Derecho Internacional Privado, núm. 8, 2008, pp. 237-255; del Pozo Pérez, Marta, "La red judicial europea en materia civil y mercantil”, en Robles Garzón, Juan Antonio y Ortells Ramos, Manuel (coords.), Problemas actuales del proceso iberoamericano, Diputación de Málaga, vol. II, 2006, pp. 615-628; en $i d$., "Reflexiones sobre la red judicial europea en materia civil y mercantil e Iber-Red", La Ley, 2007, núm. 3, pp. 1,688-1,697.

10 Accesible en el portal señalado en la nota anterior. Cfr. sobre el particular Parra García, Javier Luis, "Instrumentos para facilitar la labor de los operadores jurídicos en materia 
Particular atención merece el supuesto de información sobre ordenamientos nacionales publicada en páginas webs oficiales de instituciones internacionales (o aun de Estados soberanos), en ocasiones auspiciadas por la Unión Europea, cuya fiabilidad y actualidad resultan contrastadas; ${ }^{11}$ qué duda cabe que su uso, a efectos de información, facilitaría enormemente a las autoridades españolas la posterior prueba del derecho estatal de que se tratara, lo que encajaría en la referencia del artículo 281, apartado 2, de la Ley de Enjuiciamiento Civil a que la autoridad judicial española puede valerse de "cuantos medios de averiguación estime necesarios" para la aplicación del derecho foráneo. ${ }^{12}$ Quizá se haya perdido la oportunidad de indicarlo así expresamente en el preámbulo de la LCJIMC para un uso más generalizado y práctico de estos medios en sede jurisdiccional, notarial o registral. ${ }^{13}$ Ahora bien, tal silencio no empece la relevancia creciente que este medio de información debería adquirir en aras de la eficacia, de la celeridad y de la seguridad jurídica, como con buen criterio han señalado Alfonso Luis Calvo Caravaca y Javier Carrascosa González:

de cooperación jurídica internacional: Red Judicial Europea en materia civil y mercantil (RJECM), Red Judicial Española (REJUE), Atlas Judicial Europeo, Prontuario de auxilio judicial internacional", Práctica de Tribunales. Revista de Derecho Procesal Civil y Mercantil, núm. 28, 2006, pp. 48-57.

11 Piénsese en las webs http://wrerr.successions-europe.eu/ y http://wrwre.couples-europe.eu/ que, patrocinadas por el Consejo del Notariado de la Unión Europea, incluyen información, respectivamente, sobre el derecho sucesorio de veintidós Estados de la Unión (entre ellos España) y sobre el derecho matrimonial de los veintiocho.

12 Un palmario refrendo de esta tesis lo ha vertido la Dirección General de los Registros y del Notariado en sus más recientes resoluciones dictadas, a propósito de la inscripción en el Registro de la Propiedad de las escrituras de herencias de causantes extranjeros, uno eslovaco (fechada el 26 de julio de 2016, Boletín Oficial del Estado, núm. 227, del 20 de septiembre de 2016) y dos británicas (datadas el 28 de julio de 2016, Boletín Oficial del Estado, núm. 228, del 21 de septiembre de 2016); en ellas el citado órgano recuerda a notarios y registradores la conveniencia de ir avanzando en el conocimiento de los derechos de los demás Estados, especialmente si forman parte de la Unión Europea, en aras a facilitar la aplicación del derecho extranjero en el ámbito extrajudicial, acudiendo no sólo a los medios previstos en el artículo 36 del Reglamento Hipotecario, y excepcionalmente a los artículos de la LCJIMC, sino a los medios que proporciona el entorno E-Justicia, colaborando activamente en la resolución de conflictos de derecho internacional privado.

13 Sobre ello, véase Odriozola Mariscal, Carlos Enrique, "Aplicación del derecho extranjero a la luz de la globalización: referencia al modelo europeo", La Ley Unión Europea, núm. 31, 2015. Con un alcance más general, $c f r$. Miralles Sangro, Pedro Pablo, Aplicación del derecho extranjero en el proceso y tutela judicial, Madrid, Dykinson, 2007, pp. 140-147.

Esta obra está bajo una Licencia Creative Commons

Atribución-NoComercial-SinDerivar 4.0 Internacional, IIJ-UNAM.

Boletín Mexicano de Derecho Comparado, núm. 150, pp. 1351-1394 
...en el caso de los textos extraídos de las webpages oficiales estatales o de la UE relativos al Derecho extranjero, cabe indicar que el tribunal español puede acreditar la veracidad de dichos textos sin especiales dificultades y que, en tal caso, el valor probatorio de los mismos es muy elevado, si bien debe recordarse que dicho valor lo establece el tribunal en el caso concreto y con arreglo a las «reglas de la sana crítica». ${ }^{14}$

2) Nuestro Reino es parte en varios convenios internacionales en que se aborda la información sobre el derecho extranjero, cuyo estudio fraccionamos distinguiendo los multilaterales y los bilaterales.

a) Son dos los convenios internacionales de alcance multilateral que nuestras autoridades judiciales pueden utilizar a fin de informarse respecto al ordenamiento de otro Estado parte en los mismos.

-El primero de ellos es el Convenio Europeo acerca de la información sobre el derecho extranjero, realizado en Londres el 7 de junio de 1968, en vigor en España desde el 20 de febrero de 1974; ${ }^{15}$ aunque elaborado en el seno del Consejo de Europa está abierto a la firma de países que no pertenecen a esta organización. ${ }^{16}$ Mediante este instrumento, los Estados parte se comprometen a proporcionar a las autoridades de los demás Estados parte, información respecto a su ordenamiento jurídico y procedimiento en materia civil y mercantil, así como acerca de su organización jurisdiccional, cuando un asunto

14 Derecho internacional privado, 16a. ed., Granada, Comares, 2016, vol. I, p. 551. Los autores aluden, a mayor abundamiento (p. 554), a la información sobre ordenamientos extranjeros que el propio Consejo General del Poder Judicial contiene en su web institucional y que ha sido utilizada en diversas ocasiones para acreditar tales ordenamientos, citando a este objeto las sentencias de la Audiencia Provincial de Castellón del 15 de abril de 2010 y de la de Barcelona del 14 octubre del mismo año, ambas relativas a sendos divorcios entre cónyuges marroquíes.

15 Boletín Oficial del Estado, núm. 240, del 7 de octubre de 1974. El Convenio cuenta con un protocolo adicional hecho en Estrasburgo el 15 de marzo de 1978, publicado en el Boletín Oficial del Estado, núm. 150, del 24 de junio de 1982.

16 En él son parte, además de nuestro Reino, Albania, Alemania, Austria, Azerbaiyán, Bélgica, Bielorrusia, Bosnia-Herzegovina, Bulgaria, Costa Rica, Croacia, Chequia, Chipre, Dinamarca, Eslovaquia, Eslovenia, Estonia, Finlandia, Francia, Georgia, Grecia, Hungría, Islandia, Italia, Letonia, Liechtenstein, Lituania, Luxemburgo, Macedonia, Malta, Marruecos, México, Moldavia, Montenegro, Noruega, Países Bajos, Polonia, Portugal, Reino Unido, Rumanía, Rusia, Serbia, Suecia, Suiza, Turquía y Ucrania. 
sobre un derecho extranjero se plantee en un proceso judicial. A tal efecto, cada país designa órganos denominados "de enlace", entre los que habrá uno único de recepción (encargado de recibir las solicitudes de información provenientes de otro Estado y de darles curso) y uno o más órganos de transmisión (responsables de recibir las solicitudes provenientes de sus autoridades judiciales y de trasladarlas al órgano de recepción extranjero competente); ambas funciones son desarrolladas en España por la Subdirección General de Cooperación Jurídica Internacional del Ministerio de Justicia.

- El segundo de los instrumentos referidos es la Convención Interamericana sobre Prueba e Información acerca del Derecho Extranjero, llevada a cabo en Montevideo el 8 de mayo de 1979; sin embargo, siendo elaborada en el marco de la Organización de Estados Americanos, está abierta a la firma de países no miembros de la misma, siendo España el único de éstos que la aplica desde el 10 de enero de $1988 .{ }^{17}$ Con arreglo a las disposiciones de este tratado, las autoridades judiciales de cada uno de los Estados parte proporcionarán a las de los demás que lo solicitaran, elementos probatorios o informes sobre el texto, vigencia, sentido y alcance legal de su ordenamiento mediante cualesquiera de los medios de prueba idóneos, previstos tanto en la Ley del Estado requerido como en la del Estado requirente; a tal fin, cada país designará un autoridad central, que en el caso de España es la antes señalada Subdirección General.

b) En el marco bilateral son diversos los convenios suscritos por nuestro país con Estados de diferentes continentes en materia de cooperación judicial, en los que se contienen previsiones acerca de la mutua información de los respectivos ordenamientos jurídicos. Una clasificación de los mismos nos permitiría la siguiente distinción:

17 Boletín Oficial del Estado, núm. 11, del 13 de enero de 1988. Son parte en ella, además de nuestro Reino, Argentina, Brasil, Colombia, Chile, Ecuador, Guatemala, México, Paraguay, Perú, Uruguay y Venezuela. 
- Con países que son parte, asimismo, en el citado Convenio de Londres de 1968: es el caso de los tratados de asistencia jurídica, reconocimiento y ejecución de sentencias en asuntos civiles con Chequia y Eslovaquia del 4 de mayo de $1987 ;{ }^{18}$ de asistencia judicial en materia civil con la Federación Rusa del 26 de octubre de 1990;19 de asistencia judicial en materia civil con Bulgaria del 23 de mayo de $1993 ;{ }^{20}$ y de cooperación judicial en materia civil, mercantil y administrativa con Marruecos, del 30 de mayo de 1997. ${ }^{21}$

- Con repúblicas que son parte, igualmente, en la Convención de Montevideo de 1979: convenios de cooperación jurídica con Uruguay del 4 de noviembre de $1987^{22}$ y de cooperación jurídica en materia civil con Brasil, del 13 de abril de 1989. ${ }^{23}$

- Con Estados que son parte tanto en el Convenio de Londres de 1968 como en la Convención de Montevideo de 1979: ocurre con México, con el que tenemos firmado un acuerdo de cooperación para el intercambio de información sobre los ordenamientos jurídicos del 1o. de diciembre de $1984 .{ }^{24}$

- Con países que no son parte en ningún otro convenio multilateral: convenios de asistencia judicial en materia civil y mercantil con China, del 2 de mayo de 1992;25 con Tailandia del 15 de junio de $1998 ;{ }^{26}$ con la República Dominicana del 15 de septiembre de 2003; ${ }^{27}$ con Argelia del 24 de febrero de $2005 ;{ }^{28}$ y con Mauritania, del 12 de septiembre de 2006. ${ }^{29}$

18 Boletín Oficial del Estado, núm. 290, del 3 de diciembre de 1988.

19 Boletín Oficial del Estado, núm. 151, del 25 de junio de 1997.

20 Boletín Oficial del Estado, núm. 155, del 30 de junio de 1994.

21 Boletín Oficial del Estado, núm. 151, del 25 de junio de 1997.

22 Boletín Oficial del Estado, núm. 103, del 30 de abril de 1998.

23 Boletín Oficial del Estado, núm. 164, del 10 de julio de 1991.

24 Boletín Oficial del Estado, núm. 137, del 8 de junio de 1985.

25 Boletín Oficial del Estado, núm. 26, del 31 de enero de 1994.

26 Boletín Oficial del Estado, núm. 109, del 7 de mayo de 1999.

27 Boletín Oficial del Estado, núm. 254, del 23 de octubre de 2003.

28 Boletín Oficial del Estado, núm. 103, del 1 de mayo de 2006.

29 Boletín Oficial del Estado, núm. 267, del 8 de noviembre de 2006.

Esta obra está bajo una Licencia Creative Commons Atribución-NoComercial-SinDerivar 4.0 Internacional, IIJ-UNAM. Boletín Mexicano de Derecho Comparado, núm. 150, pp. 1351-1394 
En los casos expuestos en los tres primeros puntos en que concurran los ámbitos material, temporal y territorial de los instrumentos supraestatales indicados, no existiendo en ninguno de los convenios aludidos una cláusula expresa de compatibilidad o de exclusión entre ellos, habrá que sujetarse a lo establecido en el sistema jurídico del Estado del que proceda la petición de información. En el sistema español será menester acudir a los principios generales del derecho internacional, en buena medida derivados de los artículos 28 y siguientes del Convención de Viena sobre el Derecho de los Tratados del 23 de mayo de 1969 (aplicable en España desde 1980), como lo reitera el artículo 35 de la Ley 25/2014, del 27 de noviembre, de tratados y otros acuerdos internacionales. De ello se deriva que la norma posterior prevalece sobre la anterior, como la norma especial lo hace sobre la general; todo ello sin ignorar los principios de eficacia máxima de las soluciones o de la norma más favorable (por ejemplo, en beneficio de una parte débil, cual sería el caso del menor, del consumidor, del trabajador, etcétera). Si ello no ofreciera solución, la parte interesada tendrá en definitiva la opción de invocar el convenio que resulte de su preferencia.

b. Los mecanismos de fuente interna de naturaleza especial para obtener información sobre un derecho extranjero

Los mecanismos de los artículos 35 y 36 de la LCJIMC pueden resultar, asimismo, subsidiarios respecto de la existencia de normas especiales de fuente interna que aborden la obtención de información sobre los ordenamientos foráneos; así se ha previsto expresamente, desde la perspectiva española, respecto del primero de dichos artículos. ${ }^{30}$ De entre las leyes especiales señaladas en su disposición adicional primera, únicamente el artículo 5o., apartado 1, letra a, de la Ley 54/2007, del 28 de diciembre (de adopción internacional), dispone algo sobre el particular al establecer que corresponde a las entidades públicas organizar y facilitar la información sobre legislación, requisitos y trámites necesarios en España y en los países de origen de los menores para la adopción internacional, velando

30 Cfr. sobre ello de Miguel Asensio, Pedro Alberto, "Coordinación de la ley de cooperación jurídica internacional en materia civil con la legislación especial", Revista Española de Derecho Internacional, núm. 1, 2016, pp. 99-108. 
Esta revista forma parte del acervo de la Biblioteca Jurídica Virtual del Instituto de Investigaciones Jurídicas de la UNAM

para que dicha información sea lo más completa, veraz y actualizada posible y de libre acceso para las familias interesadas y por los organismos acreditados. ${ }^{31}$

\section{B. La técnica de la comunicación judicial directa para obtener información sobre un derecho extranjero}

El mecanismo de solicitud de información acerca de un ordenamiento extranjero previsto en el artículo 35 de la presente Ley resulta, asimismo, subsidiario respecto de la comunicación judicial directa entre autoridades españolas y extranjeras para obtener dicha información, según indica el apartado 1 del propio precepto. ${ }^{32}$

Consciente de la eficacia del mecanismo de la comunicación directa, el legislador lo incorpora y favorece en el artículo 4o. de la Ley con carácter transversal, convirtiéndolo en norma habilitante para nuestras autoridades judiciales: ${ }^{33}$ a la vez que en este ámbito concreto el apartado 3 in fine del artículo 35 insta a que sea facilitado por parte de la autoridad central

31 A ello se añaden, según se expondrá en el epígrafe III, las reglas especiales sobre consecuencias de la falta de prueba del derecho extranjero de los artículos 100, apartado 2, de la Ley 20/2011, del 21 de julio, del Registro Civil y 67, apartado 1, del texto refundido de la Ley General para la Defensa de los Consumidores y Usuarios (en la redacción aportada por la Ley 3/2014, del 27 de marzo).

32 Llama la atención que el artículo 36 no aluda al uso de la comunicación judicial directa como mecanismo para obtener información sobre el derecho español. Este vacío no impide, a nuestro entender, el uso de este tipo de comunicación sin intermediación si en el sistema jurídico del Estado requirente estuviera previsto; de ahí que las consideraciones expuestas a continuación resulten aplicables, mutatis mutandi, al supuesto inverso.

33 Tal técnica ya se contiene en algunos instrumentos supraestatales en los que España es parte en el ámbito del derecho de familia, en general, y de la responsabilidad parental, en particular. Señala el preámbulo de la ley que en la actualidad de la materia se manifiesta en la publicación por la Conferencia de La Haya de Derecho internacional privado de la Guía Emergente respecto al desarrollo de la Red Internacional de Jueces de la Conferencia de La Haya y Principios generales para las comunicaciones judiciales, incluidas las salvaguardas comúnmente aceptadas en casos específicos, dentro del contexto de la Red Internacional de Jueces de la Conferencia de La Haya. Véase, con carácter general, Forcada Miranda, J., "Las comunicaciones judiciales directas y la nueva Ley 29/2015, de 30 de julio, de cooperación jurídica internacional en materia civil: una propuesta de guía práctica para el establecimiento y desarrollo de comunicaciones judiciales directas en casos específicos”, Boletín del Ministerio de Fusticia, núm. 2,190, julio de 2016, pp. 31, 32 y 41-45. 
española (a saber, el Ministerio de Justicia exartículo 7o. de la Ley). ${ }^{34}$ La proyección de este mecanismo sobre la información del derecho extranjero daría como resultado lo siguiente:

a) La comunicación tendría lugar entre un órgano jurisdiccional español y uno extranjero sin intermediación alguna; dado que nada se indica en la LCJIMC acerca de los medios para establecerla, queda abierta cualquier posibilidad que quepa en este sentido - oral o escrita-, sin ignorar el manejo de los medios electrónicos (véase el artículo 17 de la misma).

b) Desde la óptica subjetiva española, la posibilidad de uso de esta técnica para solicitar información de un ordenamiento extranjero se limita a nuestros órganos judiciales (eso sí, a todos sin excepción, lo que da una muestra del calado de este precepto), por lo que en teoría no podrían utilizarla nuestros notarios y registradores españoles (a los que se refiere el apartado 1 del artículo 35). ${ }^{35}$ Desde la perspectiva de los Estados extranjeros, la posibilidad de recurso a esta técnica se extendería a sus órganos judiciales, naturalmente, y a cualesquiera otros que indicaran su sistema de derecho internacional privado; en teoría no podrían dirigirse a nuestros fedatarios para informarse sobre el derecho español, aunque sí a todos nuestros órganos judiciales.

c) Desde un ángulo técnico, la utilización de esta posibilidad de cooperación para obtener información acerca de un ordenamiento foráneo no podría afectar ni comprometer la independencia de los órganos judiciales involucrados; tampoco podría menoscabar los derechos de defensa

34 La concentración de la autoridad en el Ministerio de Justicia (normalmente en la Subdirección General de Cooperación Jurídica Internacional) pretende ser una respuesta útil "a la complejidad técnica actual inherente a esta materia", según el preámbulo de la Ley, como ya se hiciera, por ejemplo, por razones similares con la Oficina Central del Registro como autoridad española encargada en materia de cooperación internacional respecto de todas aquellas materias sometidas a la Ley del Registro Civil.

35 Se trata de una exclusión difícilmente justificable por cuanto la función que estos fedatarios públicos ejercen en sus respectivos campos, admite perfectamente el uso de esta técnica de comunicación directa con autoridades extranjeras de igual naturaleza para acceder al contenido del derecho de su Estado a fin de tenerlo en cuenta en España en actuaciones notariales o registrales. Una exclusión que, además, ignora el ánimo general del legislador de extender la cooperación internacional a autoridades no judiciales (infra) que, a mayor abundamiento, ha consagrado un precepto ex profeso para el uso del conducto notarial para la transmisión de ciertas solicitudes de cooperación internacional ( $c f r$. artículo 9o., letra $d$, de la Ley).

Esta obra está bajo una Licencia Creative Commons

Atribución-NoComercial-SinDerivar 4.0 Internacional, IIJ-UNAM.

Boletín Mexicano de Derecho Comparado, núm. 150, pp. 1351-1394 
de las partes, y habría de respetar en todo caso la legislación en vigor tanto en España como en el Estado extranjero de que se tratara.

\section{El mecanismo de solicitud de información acerca de un derecho extranjero}

En aquellos supuestos en que no existiera en nuestro sistema una fuente supraestatal u otra norma de origen interno de naturaleza especial que regularan esta materia y en que tampoco se hubiera utilizado la comunicación judicial directa para acceder al conocimiento de un ordenamiento extraño, los artículos 35 (apartados 1 y 3) y 36 (apartados 1 y 4) de la Ley disponen algunas reglas acerca del mecanismo que se ha de utilizar para solicitar información sobre un derecho estatal, mecanismo que el preámbulo de la misma sintetiza, en relación con el primero de los preceptos, como "proceso habilitante, pero simple y sencillo a la vez, de modo que permita obtener una hipotética respuesta". A partir de este punto, para una más sencilla sistematización, distinguiremos las solicitudes de información ad extra o activas (apartado A) de las ad intra o pasivas (apartado B).

\section{A. La solicitud de información por parte de autoridades españolas}

En aquellos supuestos en que habida cuenta de su carácter subsidiario resultara de aplicación el artículo 35 de la LCJIMC, en sus apartados 1 y 3 , se disponen las siguientes reglas acerca del mecanismo que han de utilizar las autoridades españolas para solicitar información sobre el derecho de un Estado extranjero.

1. De entrada, la petición de información debe estar orientada a su uso "en un proceso judicial español o por una autoridad española en el marco de sus competencias".

2. Seguidamente deberá cursarse un oficio por la autoridad española que corresponda.

3. A continuación, el mismo deberá elevarse a la autoridad central española.

4. Con posterioridad ésta hará llegar la solicitud en cuestión a las autoridades competentes del Estado requerido por la vía consular o diplomática, o a través de su autoridad central (si existiera y así estuviera previsto en su ordenamiento). 
5. Finalmente, aunque nada se indique en la LCJIMC, la autoridad central española, una vez reciba la información requerida, la trasladará a la autoridad, igualmente española que la solicitó.

El éxito final de todo este proceso no está asegurado, pues depende de la voluntad y posibilidad de cooperación de las autoridades extranjeras requeridas que no están jurídica ni políticamente vinculadas por nuestra Ley; de ahí que ésta, con prudencia y realismo, señale en su preámbulo que "no deben generarse falsas expectativas, pues... no hay garantía alguna de que las autoridades extranjeras accedan a proporcionar dicha información". ${ }^{36}$

Expuesto esto, suscita dudas la confrontación entre el desarrollo del mecanismo del artículo 35 de la Ley, que acabamos de analizar, y la redacción de la letra $e$ del artículo 8o. de la misma norma, en la que se indica que corresponde a la autoridad central española "(p)roporcionar información sobre Derecho extranjero, conforme a lo dispuesto en los artículos 34 y 35”. En el primer caso se diseña un mecanismo en el que la autoridad central española se ceñiría a recibir las solicitudes de autoridades, asimismo, españolas que desearan obtener información sobre un ordenamiento extranjero limitándose a tramitarlas conforme al iter expuesto. En el segundo supuesto, en cambio, se establecería como función de la autoridad central española la de proporcionar por sí misma dicha información. Aunque las dudas parecen disiparse si se tiene presente que el artículo 8o., letra $e$, se remite a lo dispuesto en el artículo 35 (lo que implicaría hacer prevalecer la función prevista en éste de mera tramitación de las solicitudes), la cuestión no es baladí; en efecto, a nuestro entender la autoridad central española tiene la obligación de tramitar las solicitudes de información conforme a lo previsto en el artículo 35 y la facultad de proveer por sí misma la información a la autoridad española requirente si dispusiera de ella (piénsese, por ejemplo, en la existencia en el Ministerio de Justicia de un repositorio o base de datos de ordenamientos extranjeros que pudiera utilizarse a estos fines en aras de la economía procesal y de la celeridad de la cooperación). ${ }^{37}$

36 Así lo recalca el citado Informe del Consejo General del Poder Judicial del 30 de septiembre de 2014 acerca del anteproyecto de la Ley aprobado por el gobierno el 4 de julio de 2014, p. 14, al afirmar que en este campo carece de sentido el principio de reciprocidad.

37 No se olvide que, favor cooperationis, el artículo 3o., apartado 4, de la Ley aboga por la celeridad en la práctica de la cooperación jurídica internacional al ordenar sin 


\section{B. La solicitud de información por parte de autoridades extranjeras}

En aquellos supuestos en que habida cuenta de su carácter subsidiario, resultase de aplicación el artículo 36 de la LCJIMC, en sus apartados 1 y 4 se disponen las siguientes reglas acerca del mecanismo que han de utilizar las autoridades extranjeras para solicitar información sobre el derecho español.

1. De entrada, la petición de información debe estar condicionada a su uso "en un proceso judicial extranjero o por una autoridad extranjera en el marco de sus competencias", lo que podría dar a entender que la autoridad española requerida habría de verificar el cumplimiento de tal condición para prestar su colaboración, lo que no parece lógico.

2. Dicha solicitud deberá estar dirigida por la autoridad extranjera requirente a la autoridad central española, que bien podrá responderla directamente, bien podrá reenviarla a otros organismos públicos o privados. ${ }^{38}$ Esta última previsión resulta lo suficientemente imprecisa como para generar diversos interrogantes.

a) En primer término se ha criticado la referencia a esos otros organismos, y en expresión del Consejo General del Poder Judicial:

...no queda claro que organismos ajenos al Ministerio estén efectivamente obligados a dar respuesta. Tampoco es fácil identificar a qué se refiere la

excepción que las solicitudes de cooperación jurídica internacional se lleven a cabo y ejecuten sin dilación (en ello incide, asimismo, el artículo 13), además conforme a los principios de flexibilidad (se entiende que teniendo en consideración las circunstancias de cada supuesto) y coordinación (se supone que con las autoridades extranjeras y con el resto de las españolas).

38 Pese al mandato del artículo 3o. de la Ley a las autoridades españolas de cooperar con las autoridades extranjeras (apartado 1) sin condición de reciprocidad, en el caso en que las de un Estado denegaran reiteradamente la cooperación con las españolas o dispusiesen de un mandato legal de no prestarla, el gobierno español podría, mediante real decreto, establecer que nuestras autoridades no cooperasen con las de dicho Estado (apartado 2). Si bien esta fórmula puede parecer contradictoria acaso se halle justificada con la idea de evitar a las autoridades españolas un esfuerzo material de seguir cooperando con las de aquellos Estados que en absoluto lo hagan con el nuestro; el Consejo de Estado, en la página 8 de su referido Dictamen sobre el anteproyecto de la ley aprobado por el gobierno, considera acertada esta regla, "en la medida en que permite una mayor flexibilidad en la respuesta del Estado y un más adecuado equilibrio entre la garantía del derecho a la tutela judicial efectiva y el respeto a los principios básicos que rigen las relaciones internacionales". 
mención a «organismos privados», debiendo extremarse la precaución pues la elaboración de informes sobre el Derecho español es tarea habitual de abogados y otros profesionales del Derecho, no quedando claro cómo va a seleccionar el Ministerio a los profesionales a los que va a remitir las solicitudes. ${ }^{39}$

Tampoco se aclara, si reenviada la solicitud de información por la autoridad central española a otro organismo patrio público o privado, será éste el que remita la respuesta a la autoridad extranjera requirente. A nuestro entender, en ausencia de comunicación directa tal organismo habrá de remitir su información a la autoridad central española, debiendo ser ésta la que a su vez la transmita a la autoridad extranjera requirente; en apoyo de este parecer se hallaría la redacción inicial de la letra $e$ del artículo 8o. de la LCJIMC, que dispone que corresponde a la autoridad central española "(p)roporcionar información sobre Derecho español cuando proceda con arreglo a lo previsto en el artículo 36".

b) A este propósito, a diferencia del artículo 35, no se señala en el 36 cómo se ha de remitir la información sobre el derecho español a la autoridad extranjera requirente. Por analogía a lo establecido en aquel precepto, la misma se le haría llegar por la vía consular o diplomática, o a través de su autoridad central (si existiera y así estuviera previsto en su ordenamiento).

\section{Las autoridades intervinientes en la solicitud de información sobre un ordenamiento extranjero}

La sensible disparidad de los artículos 35 (solicitudes activas o ad extra) y 36 (solicitudes pasivas o ad intra) nos obliga a abordarlos separadamente.

\section{A. La solicitud de información por parte de autoridades españolas}

Son dos las autoridades intervinientes en nuestro país en el mecanismo de solicitud de información acerca de un derecho foráneo: en un extremo la autoridad central española (que es la que recibe la solicitud) y en el otro

39 Informe acerca del anteproyecto de la Ley aprobado por el gobierno, cit., p. 29.

Esta obra está bajo una Licencia Creative Commons

Atribución-NoComercial-SinDerivar 4.0 Internacional, IIJ-UNAM.

Boletín Mexicano de Derecho Comparado, núm. 150, pp. 1351-1394 
extremo otra autoridad española (que previamente la ha formulado para utilizar la información requerida en el marco de sus competencias).${ }^{40}$ En concreto, el apartado 1 del artículo 35 concreta esta última autoridad tanto en los órganos judiciales como en los notarios y registradores.

1. En relación con los primeros, se ha señalado, ya que sin restricción en cuanto a su naturaleza pueden recurrir ora a este mecanismo, ora al de la comunicación judicial directa para obtener información sobre un ordenamiento extranjero.

2. Respecto de los segundos, la referencia expresa a notarios y registradores en este precepto es una manifestación más de la relevancia atribuida al papel desempeñado por estos fedatarios en el tráfico jurídico externo. En efecto, en lo que atañe al elemento subjetivo de la cooperación, la LCJIMC parte de una visión amplia, por cuanto supera la perspectiva únicamente judicial de la misma para plausiblemente abarcar también la cooperación de autoridades de otra índole, como es el caso de los notarios y de los registradores. ${ }^{41}$ Así lo acredita la propia rúbrica de la Ley, que hace referencia al carácter jurídico de la cooperación internacional en lugar de a la naturaleza judicial de la misma (adjetivo que sigue utilizando el artículo 177 de la Ley de Enjuiciamiento Civil). ${ }^{42}$

\section{B. La solicitud de información por parte de autoridades extranjeras}

Dos son las autoridades intervinientes en el mecanismo de solicitud de información acerca del derecho español: en un extremo la autoridad central española (que, según acabamos de explicar, es la que recibe la soli-

40 Precisa Francisco José Garcimartín Alférez (Derecho internacional privado, 3a. ed., Madrid, Civitas, 2016, p. 243), que es posible que la solicitud de información por parte de estas autoridades venga precedida a su vez por una petición de las partes para que la lleven a cabo.

41 El preámbulo de la Ley señala que la cooperación jurídica internacional debe abordar también el ámbito extrajudicial en cuanto representa la normalidad de las relaciones jurídicas económicas y familiares.

42 Este precepto, que no ha sido objeto de modificación por la Ley 42/2015, de 5 de octubre (Boletín Oficial del Estado, núm. 239, de 6 de octubre), pierde sustantividad por cuanto alude, como fuentes para disciplinar los despachos para la práctica de las actuaciones judiciales de las autoridades españolas en el extranjero y de las foráneas en España (esto es, la cooperación tanto activa como pasiva), a los instrumentos supraestatales y a la legislación interna que resulte aplicable que es, desde el 20 de agosto de 2015, la LCJIMC. 
citud) y en el otro extremo una autoridad extranjera que la ha formulado para utilizar la información requerida en un proceso judicial o en el marco de sus competencias.

1. En lo que concierne a la primera, advierte con razón el aludido Informe del Consejo General del Poder Judicial que la obligación de la autoridad central española de proporcionar información sobre el derecho español a autoridades extranjeras también en aquellos supuestos en los que no está previsto en la normativa internacional y europea implica un aumento de las cargas administrativas que posiblemente no se ha valorado adecuadamente en relación con los medios existentes en la actualidad para llevar a cabo las actuaciones previstas. ${ }^{43}$

2. En lo que atañe al otro elemento subjetivo, las autoridades extranjeras, el apartado 1 del artículo 36 - como no podría ser de otro modono concreta de qué tipo de autoridad ha de tratarse, pues ello es cuestión a la organización de cada Estado soberano; es más, ni siquiera se establece que las solicitudes provenientes del extranjero deban ser transmitidas a nuestra autoridad central a través de la autoridad central del país en cuestión, ya que es posible que en éste no exista tal figura. ${ }^{44}$

No obstante lo anterior, el artículo 36 apunta indirectamente tanto a autoridades jurisdiccionales (al referirse a que el uso de la información sobre el derecho español puede ser utilizada en un proceso judicial extranjero) como a otro orden de autoridades no judiciales (al aludir a su utilización por una autoridad extranjera en el marco de sus competencias), cual podría ser el caso de figuras similares o cercanas a nuestros notarios y registradores. Ello resulta lógico por la plausible manifestación de la relevancia atribuida al papel desempeñado por estos fedatarios en el tráfico jurídico externo a la que se acaba de aludir.

43 Página 18.

44 Se estaría consagrando de este modo una suerte de comunicación judicial entre cualquier autoridad de cualquier Estado extranjero y nuestra autoridad central; qué duda cabe de que de existir también una autoridad central en dicho Estado lo ideal sería que fuera ella la que canalizara las peticiones de información de derecho español efectuadas por los órganos de su país para dirigirlas a la autoridad central española.

Esta obra está bajo una Licencia Creative Commons

Atribución-NoComercial-SinDerivar 4.0 Internacional, IIJ-UNAM.

Boletín Mexicano de Derecho Comparado, núm. 150, pp. 1351-1394 


\section{El contenido de las solicitudes de información acerca del derecho extranjero}

Analizados el mecanismo para solicitar información sobre un ordenamiento foráneo, así como las autoridades que intervienen en el mismo, procede seguidamente abordar la cuestión relativa al contenido de la solicitud de información remitida desde España a otro país, o viceversa. A ello atañen los apartados 4 del artículo $35^{45}$ y 3 del artículo 36, que establecen las cuestiones que debe incluir la misma: ${ }^{46}$

1. La autoridad - judicial o no- requirente, con mención de su dirección postal o electrónica. Esta última precisión resulta coherente con el relieve que la Ley otorga al uso de los medios técnicos y electrónicos a lo largo de su texto, especialmente en el artículo 17, al que ya se ha aludido.

2. La naturaleza del asunto, que en todo caso concernirá bien a un proceso judicial, bien a una materia propia de la competencia de otra autoridad (en España, por ejemplo, de un notario o de un registrador).

3. Una exposición detallada de los hechos que motivan la solicitud, que pondrán de manifiesto la necesidad o conveniencia de conocer algún extremo del ordenamiento de otro país. ${ }^{47}$

4. Los elementos probatorios concretos que se solicitan, expresión que no resulta todo precisa que debiera por cuanto da a entender que la información obtenida será utilizada para probar un derecho extranjero, cuando no tiene por qué ser necesariamente así.

5. Las copias de aquellos documentos que se consideren imprescindibles para precisar su alcance, que el artículo 35, apartado 4, permite incorporar a la solicitud de información.

45 Por lógica, los detalles de dicho contenido habrán ser previamente transmitidos por la autoridad española (judicial, notarial o registral) interesada a nuestra autoridad central para que a su vez pueda trasladarlos a la autoridad extranjera requerida.

46 Estos preceptos vienen a ser una concreción - si no una reiteración - de lo dispuesto en el artículo 10 de la propia Ley, acerca del contenido y de los requisitos mínimos de las solicitudes de cooperación, que han de ser verificados por la autoridad central española y que serían exigibles a las solicitudes cursadas tanto por autoridades extranjeras destinadas a las españolas como viceversa.

47 Téngase presente que la LGJIMC contiene una novedosa norma de carácter general de protección de datos en el artículo 19 que, siendo fruto de un equilibrio entre las necesidades que requiere la cooperación internacional y el respeto de la citada protección, debe ser respetada en este punto. 
El contenido de la solicitud, así conformado, habrá de ser debidamente traducido al idioma de la autoridad requerida. Sobre este particular, téngase presente que la Ley dispone de una norma ad hoc, el apartado 1 del artículo 11.48

\section{El objeto de las solicitudes de información acerca de un ordenamiento extranjero}

El iter lógico del análisis que venimos efectuando en estas páginas nos conduce a abordar seguidamente el objeto o finalidad de las solicitudes de información sobre un derecho extraño. Los artículos 35 y 36 dedican a la cuestión sus respectivos apartados 2, indicando que tales solicitudes podrán contener la petición de informes de autoridades, dictámenes periciales de juristas expertos, jurisprudencia, textos legales certificados y cualquier otra que se estime relevante. Nos hallamos, según se avanzó, ante una regla cuya existencia resulta cuestionable por una doble razón. Por una parte, porque el artículo 34 podría bastar a este fin al disciplinar a qué puede referirse la información sobre un derecho extranjero. Por lo que el precepto del apartado 2 de los artículos 35 y 36 sería prescindible. Por otra parte, dado que la relación de documentos descrita en ambos preceptos parece de nuevo revelar la confusión del legislador entre la información sobre un ordenamiento extranjero y su prueba, pues tal relación - al menos buena parte de ella - lo es más bien de medios para acreditar el contenido y la vigencia del derecho extranjero, por lo que acaso debería estar ubicada en el artículo 33.

48 La LCJIMC contiene otro artículo con idéntica rúbrica "Idioma", el 25, ubicado en el capítulo II "De los actos de notificación y traslado de documentos judiciales" del mismo título I. La duplicidad de normas sobre la misma materia se explicaría en razón del objeto de la traducción: en tanto que en el artículo 11 se disciplinaría la de las solicitudes de cooperación jurídica internacional propiamente dichas (esto es, del vehículo o medio utilizado para pedirla), en el artículo 25 se abordaría la traducción de los documentos notificados o trasladados. Ahora bien, desafortunadamente ello no resulta así de claro por cuanto en los dos apartados del artículo 11 (cooperación ad extra y ad intra, respectivamente) se alude a la traducción de las solicitudes y de "sus documentos adjuntos", lo que genera una confluencia de ámbitos substantivos de aplicación de ambos artículos y una criticable disparidad de consecuencias jurídicas o soluciones. Para salvar estas disfunciones resulta preferible entender que el régimen de traducción de los documentos, objeto de notificación o traslado ha de ser íntegramente el del artículo 25 y no el del artículo 11, que debe limitarse al idioma de las solicitudes de cooperación jurídica internacional.

Esta obra está bajo una Licencia Creative Commons

Atribución-NoComercial-SinDerivar 4.0 Internacional, IIJ-UNAM.

Boletín Mexicano de Derecho Comparado, núm. 150, pp. 1351-1394 
Expuesto lo anterior, los artículos 35 y 36 permiten que este tipo de solicitudes de cooperación puedan tener por objeto la petición a la autoridad requerida de informes de autoridades, de dictámenes periciales de juristas expertos, de jurisprudencia, de textos legales certificados y de cualquier otro que se estime relevante (lo que evidencia que se trata de un listado no exhaustivo).

\section{La financiación de las solicitudes de información sobre el derecho extranjero}

Finaliza nuestro análisis de este capítulo con la cuestión concerniente a la financiación de las solicitudes de información acerca de un ordenamiento extranjero, que el apartado 5 de los artículos 35 y 36 establece de forma sencilla y clara al disponer que cuando se solicite un elemento probatorio - de nuevo la confusión entre información y prueba- que suponga un coste, el mismo será a cargo de la parte solicitante, pudiendo ser exigida en este caso con la provisión de fondos.

1. En el supuesto de solicitud de información sobre un ordenamiento extranjero efectuada por una autoridad española, no se distingue si se entiende por "solicitante" a la autoridad española propiamente dicha, al particular que hubiera hecho llegar a ésta la petición de solicitar información sobre un derecho foráneo o ambas. ${ }^{49}$ En la práctica, si la autoridad extranjera exigiera el pago de alguna cantidad por la información solicitada por la autoridad central española, ésta lo comunicaría a la autoridad española a quo para que, si lo considerara, solicitara a su vez provisión de fondos a la parte interesada. ${ }^{50}$

2. En el caso de la solicitud de información sobre el derecho español cursada por una autoridad extranjera, nuestro legislador se muestra tajante en un doble sentido: por una parte atribuyendo la obligación pecuniaria sólo a la autoridad requirente (otra cosa será que pueda repetir el gasto al particular interesado en la información), y por otra parte recalcándolo con el adverbio siempre.

49 Del citado Informe del Consejo General del Poder Judicial, página 21, se desprende que la expresión solicitante abarcaría a ambas.

50 Los autores agradecen las explicaciones ofrecidas por doña Laura Fernández Domínguez, jefe de Servicio de Auxilio Judicial Civil de la Subdirección General de Cooperación Jurídica Internacional del Ministerio de Justicia.

Esta obra está bajo una Licencia Creative Commons Atribución-NoComercial-SinDerivar 4.0 Internacional, IIJ-UNAM. Boletín Mexicano de Derecho Comparado, núm. 150, pp. 1351-1394 
Lo cierto es que ambas normas (los artículos 35 y 36) resultan una concreción del régimen general de los gastos y costas derivados de la tramitación y ejecución de las solicitudes de cooperación jurídica internacional disciplinado en el artículo 18 de la LCJIMC, que establece que los mismos serán a cargo de aquellos a cuya instancia se soliciten, no estando la autoridad central española obligada a asumir gasto alguno — "en ningún caso" subraya el preámbulo de la misma - en relación con las solicitudes presentadas.

\section{LA PRUEBA DEL DEREGHO EXTRANJERO POR LAS AUTORIDADES ESPAÑOLAS}

En el bloque anterior hemos analizado lo relativo a la información acerca de un derecho extraño a quien la solicita (sea uno extranjero cuando la solicita una autoridad española, sea el español cuando la solicita una autoridad extranjera). En este último bloque del presente trabajo abordamos la prueba propiamente dicha de un ordenamiento extranjero ante la autoridad española, cuestión que se ha de centrar en el contenido del artículo 33 de la LCJIMC. Para ello comenzaremos resaltando las principales novedades que ésta aporta (epígrafe 1); las proyectaremos sobre la regulación contenida en la Ley de Enjuiciamiento Civil, a la que el artículo se remite (epígrafe 2), y concluiremos con la aplicación de la ley española en caso de la no acreditación por las partes del contenido y vigencia del derecho extranjero (epígrafe 3).

\section{Las principales novedades en materia de prueba del derecho extranjero}

En lo que se refiere a la prueba del derecho extranjero, se efectúa de entrada en el artículo 33 de la LCJIMC una remisión de la prueba de su contenido y vigencia a lo dispuesto en la Ley de Enjuiciamiento Civil (en concreto, artículo 281.2) y demás disposiciones aplicables en la materia (entre las que se hallaría el artículo 36 del Reglamento Hipotecario, el artículo 91 del Reglamento del Registro Civil o el artículo 168.I.4 del Re- 
glamento Notarial). ${ }^{51}$ Dicho esto, y centrados en la aplicación judicial del derecho extranjero, podría considerarse en apariencia que poco aporta el nuevo el artículo 33 LJIMC al vigente panorama de la aplicación del derecho extranjero por nuestros órganos judiciales. ${ }^{52}$ Nada más lejos de la realidad, pues lo cierto es que algunas cuestiones interesantes ha aportado el artículo 33, como se podrá apreciar a lo largo de las siguientes páginas. De entrada podemos destacar tres novedades:

1. En primer término, la inclusión de una referencia expresa al uso, por parte de los órganos judiciales, del criterio de valoración de las "reglas de la sana crítica" de la prueba practicada para determinar su valor a los fines de acreditar el contenido y vigencia del derecho extranjero. ${ }^{53}$ Se persigue con ello recalcar la relevancia del papel del juzgador en este campo y del necesario equilibrio en la toma en consideración de los múltiples factores que inciden en la prueba de un derecho extraño. Y es que nos hallamos ante una norma abierta, de gran flexibilidad, que claramente precisará desarrollo jurisprudencial para ser adecuadamente perfilada.

2. En segundo lugar, se alude en el artículo 33, igualmente como novedad normativa, al medio de prueba que representan los "informes" o "dictámenes" emitidos sobre derecho extranjero (que, naturalmente, care-

51 En realidad, el artículo 33.1 de la LGJIMC remite la regulación de la prueba del contenido y vigencia del derecho extranjero a la Ley de Enjuiciamiento Civil: “(y) demás disposiciones aplicables a la materia". Pero lo cierto es que, al margen de la referida Ley (y alguna norma especial sobre todo en relación al ejercicio de la actividad notarial y registral - infra-), no existen en la actualidad normas de derecho internacional público, de derecho de la UE, o contenidas en convenios internacionales, sobre prueba del derecho extranjero. De ahí que Alfonso Luis Calvo Caravaca y Javier Carrascosa González indiquen que el referido artículo 281.2 constituye "la bóveda de todo el régimen jurídico de la prueba del derecho extranjero en el sistema español”. (Derecho..., cit. (16a. ed.), pp. 536 y 537).

52 Llama la atención de entrada que no se haya aprovechado la oportunidad de la promulgación de esta Ley ni de la reforma de 2015 de la Ley de Enjuiciamiento Civil para añadir al contenido y a la vigencia el requisito de la prueba, asimismo, de la interpretación del derecho foráneo, creación de nuestra jurisprudencia. Ello podría considerarse como una desautorización por el legislador hacia tal doctrina; en sentido contrario, María del Carmen Vaquero López critica a éste por no haber incluido en el artículo 33 de la LCJIMC, la exigencia de la "interpretación y aplicabilidad" al caso del derecho extranjero (op. cit., p. 217).

53 Una objeción al criterio de la sana crítica en esta sede se contenía en la página 13 del citado informe del Consejo Fiscal sobre el anteproyecto de Ley elaborado por el gobierno. 
cerían de alcance vinculante). Con esta otra regla se abre la puerta a posibles concreciones de este medio de prueba siempre que conforme a la sana crítica el juzgador considere acreditado el derecho extranjero, hallándose entre tales concreciones los informes o dictámenes elaborados por un jurista (no necesariamente dos ni prácticos del derecho, ni del país de que se trate); ${ }^{54}$ así se ha venido admitiendo de facto en nuestros tribunales, por ejemplo, al considerarse acreditado el contenido y vigencia de un ordenamiento foráneo mediante dictámenes de profesores universitarios españoles. ${ }^{55}$

3. Finalmente, para cerrar este avance, no menos importante resulta la solución consagrada ante la falta de acreditación por las partes del contenido y vigencia del derecho extranjero en la marco de un corpus normativo heterogéneo, si no contradictorio. ${ }^{56}$ Sienta el artículo 33.3 de la LCJIMC como regla general, la facultad de nuestra autoridad de aplicar en tales casos el derecho español, lo que requiere de ésta ponderar las circunstancias objetivas y subjetivas - en particular la actitud de las par-

54 Los artículos 35.2 y 36.2 de la Ley, en sede de información sobre el derecho extranjero y español, aluden a "dictámenes periciales de juristas expertos".

55 Calvo Caravaca, Alfonso Luis y Carrascosa González, Javier, Derecho internacional privado, 15a. ed., Granada, Comares, 2014, vol. I, p. 481, invocan como ejemplos de acreditación del derecho aplicable al régimen económico de sendos matrimonios, la sentencia de la Audiencia Provincial de Huesca del 14 de diciembre de 2005, que admitió un dictamen sobre el ordenamiento marroquí de la profesora María del Pilar Diago Diago, de la Universidad de Zaragoza, y la sentencia de la Audiencia Provincial de Murcia del 10 de julio de 2009, que hizo lo propio con un dictamen del profesor Javier Carrascosa González, sobre el ordenamiento del estado de Ohio (Estados Unidos).

56 En tanto que el artículo 100.2 de la Ley del Registro Civil de 2011 señala que la falta de acreditación del contenido y vigencia del ordenamiento extranjero aplicable a los hechos y actos relativos al estado civil supondrá la denegación de la inscripción de éstos, el artículo 67.1 del texto refundido de la Ley General para la Defensa de los Consumidores y Usuarios (en la redacción aportada por la Ley 3/2014, de 27 de marzo) indica que: "(c) uando no se haya podido determinar el contenido de la Ley extranjera, se aplicará subsidiariamente la Ley material española”. Una explicación racional de esta disparidad podría hallarse en lo siguiente: en tanto que en el primer supuesto el rigor que exige la estabilidad y seguridad del estado de la persona desaconseja no modificar su situación registral, sino se prueba el derecho extranjero, en el segundo el animus protectionis de la parte débil aconseja no privar a ésta de un derecho por la ausencia de prueba del ordenamiento extranjero, procurándole en todo caso la aplicación del derecho español a fin de garantizarle el disfrute de tal derecho. En relación con esta última disposición, véase un análisis crítico de Miguel Asensio, Pedro, op. cit., pp. 100 y 101.

Esta obra está bajo una Licencia Creative Commons

Atribución-NoComercial-SinDerivar 4.0 Internacional, IIJ-UNAM.

Boletín Mexicano de Derecho Comparado, núm. 150, pp. 1351-1394 
tes - del asunto para ejercer o no tal facultad; ${ }^{57}$ se persigue así tanto la evitación de una denegación de justicia (que podría ser injustificada si se desestimara la demanda) como la búsqueda de la efectiva tutela judicial. ${ }^{58}$ Esta solución, no carente de importantes críticas - infra-, se entiende que ha de ser utilizada "con carácter excepcional"; 59 si bien la frecuencia con que en la práctica no se prueba el contenido y vigencia del derecho extranjero - por razones objetivas o subjetivas - hace sospechar que su utilización resultará asidua. ${ }^{60}$

Destacadas la principales novedades que en primera lectura reporta en esta materia el artículo 33 de la LCJIMC, ha de indicarse, sin embargo, que la nueva regulación aprobada por el legislador español (y atendiendo también a la regulación básica ya contenida en el artículo 281.2 de la Ley de Enjuiciamiento Civil) dará lugar a que en la práctica sigan surgiendo serios problemas en relación con los distintos aspectos vinculados con la prueba del contenido y vigencia del derecho extranjero. Y ello en tanto que, como veremos, las tradicionales cuestiones que se venían histórica-

57 Extiende Pedro Miguel Asencio esta solución también a los supuestos de imposibilidad jurídica de aplicación del derecho extranjero, típicamente como consecuencia de la reserva de orden público ("Comentario a la Ley 29/2015, de cooperación jurídica internacional en materia civil...", cit.).

58 Señala el preámbulo que, de entre las dos soluciones que en esencia se dan a este controvertido aspecto en la práctica forense - la desestimación de la demanda y la aplicación de la lex fori - , la nueva Ley "se decanta por esta última solución, que es la tradicional en nuestro sistema y la mayoritaria en los sistemas de derecho internacional privado de nuestro entorno".

59 Por ello entiende el Consejo de Estado en la p. 11 de su aludido dictamen que la decisión del órgano judicial de aplicar subsidiariamente el derecho material español en tanto que lex fori debería estar suficientemente motivada.

60 En tal línea se pronuncia Vaquero López, María del Carmen, op. cit., p. 217. No obstante, de contrario parecer es el preámbulo de la Ley, la cual señala que "(d)ebe entenderse que la falta de prueba del Derecho extranjero dentro de un proceso judicial es algo excepcional que solo sucederá cuando las partes no consigan probar el Derecho extranjero y sin olvidar la posibilidad de que el tribunal coopere en la acreditación de dicho contenido". En el mismo sentido de excepcionalidad en la aplicación se pronuncian Calvo Caravaca, Alfonso Luis y Carrascosa González, Javier, Derecho..., cit. (16a. ed.), pp. 579 y 580). En cualquier caso habrá de estarse a la interpretación que hagan los tribunales del carácter excepcional, esto es, de cuándo se entenderá que realmente no ha podido acreditarse el derecho extranjero para que entre en juego la solución del artículo 33.3. 
mente planteando en este ámbito no han sido objeto de un tratamiento y, por lo tanto, de una solución en la nueva norma.

\section{La prueba del derecho extranjero en el marco de la Ley de Enjuiciamiento Civil}

Seguidamente destacaremos las principales cuestiones que surgen respecto a la prueba del derecho extranjero para, al hilo de su análisis, comentar en qué medida afecta a ello la nueva regulación contenida en el artículo 33 de la LCJIMC. Y dado que éste se remite en su apartado 1 a las normas de la Ley de Enjuiciamiento Civil en lo que se refiere a la regulación de la prueba del contenido y vigencia del derecho extranjero (en esencia, a su artículo 281.2), a continuación destacaremos las principales características que se deducen de ésta, enlazando dicha exposición con la incidencia que al respecto tendrá la nueva regulación contenida en la LCJIMC. ${ }^{61}$

\section{A. El objeto de prueba e información del derecho extranjero}

Como señalan Alfonso Luis Calvo Caravaca, y Javier Carrascosa González, la expresión "derecho extranjero" comprende la totalidad del ordenamiento extranjero, incluyendo todas sus normas jurídicas, esto es, las normas escritas de producción interna e internacional, costumbre y todas las demás reglas que tengan la condición de derecho objetivo en el Estado donde han sido creadas. ${ }^{62}$

61 La doctrina tras la entrada en vigor de la LCJIMC se refiere a la existencia de un doble sistema de regulación de la prueba del derecho extranjero en España: por un lado, el "sistema de textura abierta" (contenido en el artículo 281.2 de la Ley de Enjuiciamiento Civil) y por otro, el sistema reglamentista (el del artículo 33 de la LCJIMC). Sin embargo, este último ni ha colmado todas las lagunas del artículo 281.2, ni las que ha colmado lo ha hecho de un modo acertado. (Calvo Caravaca, Alfonso Luis y Carrascosa González, Javier, "La prueba del derecho extranjero en la nueva ley española de Enjuiciamiento Civil 1/2000", Diario La Ley, núm. 6178, 28 de enero de 2005, p. 2, y Calvo Caravaca, Alfonso Luis, "La aplicación judicial del derecho extranjero en España. Consideraciones críticas", Revista Española de Derecho Internacional, núm. 2, 2016, p. 138).

62 Así, la jurisprudencia, los principios generales del derecho o la equidad (sentencia de la Audiencia Provincial de Alicante del 5 de octubre de 2010 o sentencia del Tribunal Superior de Justicia de Cataluña — social — del 13 de mayo de 2009). También estarían

Esta obra está bajo una Licencia Creative Commons

Atribución-NoComercial-SinDerivar 4.0 Internacional, IIJ-UNAM.

Boletín Mexicano de Derecho Comparado, núm. 150, pp. 1351-1394 
En efecto, con relación a la prueba del derecho extranjero, tanto el artículo 33 de la LCJIMC (en sus apartados 1, 2 y 3) como el artículo 281.2 de la Ley de Enjuiciamiento Civil (al cual remite el artículo 33.1 la regulación de la prueba del contenido y vigencia del derecho extranjero) determinan que, en principio, lo que ha de probarse es el "contenido" y la "vigencia" del derecho extranjero.

Pues bien, si seguimos literalmente lo indicado en los citados preceptos, bastaría con probar el contenido y vigencia del derecho extranjero para tenerlo por acreditado. ${ }^{63}$ Pero en tal caso habría que preguntarse si con la mera prueba de su contenido y vigencia estaría el juez o la autoridad competente española en disposición de aplicar dicho derecho extranjero tal como lo haría en su caso un juez o autoridad del Estado al cual pertenece tal derecho y sin que le suscitara la menor duda razonable su aplicación. Evidentemente, parece que ello no sería así, ya que aun probándose el contenido de la norma extranjera junto a la acreditación de su vigencia puede ocurrir que el juez en España mantuviera serias dudas de su aplicación al caso concreto. ${ }^{64}$

Por tal razón, el Tribunal Supremo viene exigiendo desde hace tiempo y de una manera reiterada una prueba más exhaustiva del derecho ex-

comprendidos en el concepto de derecho extranjero los convenios colectivos vigentes en el ordenamiento extranjero (sentencia del Tribunal Superior de Justicia de Madrid - social- del 14 octubre de 2015). Y el objeto de la prueba puede recaer sobre derecho privado o de derecho público extranjero, pues el artículo 281.2 de la Ley de Enjuiciamiento Civil es una norma general, y no es extraño el supuesto en el que haya de acreditarse una norma extranjera de derecho público; por ejemplo, la normativa administrativa de extranjería o el derecho fiscal extranjero (Calvo Caravaca, Alfonso Luis y Carrascosa González, Javier, Derecho..., cit. (16a. ed.), p. 558).

63 Estaríamos entonces ante la "tesis de la prueba mínima" del derecho extranjero (ibidem, p. 559). Algún pronunciamiento aislado ha mantenido que es suficiente acreditar el contenido y vigencia del derecho extranjero con base en que el artículo 281.2 de la Ley de Enjuiciamiento Givil no exige nada más (en particular, sentencia del Tribunal Superior de Justicia de Madrid, del 29 de octubre de 2003).

64 Defendiendo una tesis amplia de la prueba del derecho extranjero, Federico Garau Sobrino expresa que: "limitar el objeto de la prueba al contenido y vigencia podría poner en peligro el principio jurisprudencial de que el tribunal español debe fallar de la manera más semejante posible a como lo haría un tribunal del país cuyo Derecho aplica". "La prueba del derecho extranjero en la nueva Ley de Enjuiciamiento Civil", Revista General del Derecho, núm. 678-679, marzo-abril de 2001, p. 2352). En similar sentido sobre la necesidad de acreditación de la interpretación del derecho extranjero, véase Esplugues Mota, Carlos et al., Derecho internacional privado, 10a. ed., Valencia, Tirant lo Blanch, 2016, p. 358. 
tranjero, la cual garantice que la aplicación de dicho ordenamiento no va a suscitar duda razonable alguna a los tribunales españoles. ${ }^{65}$ Es por ello que, siguiendo a Alfonso Luis Calvo Caravaca y Javier Carrascosa González, los aspectos del derecho extranjero que en la práctica han de probarse ante los tribunales y otras autoridades españolas serían los siguientes: ${ }^{66}$

a) En primer término, es necesario acreditar el "contenido literal" del derecho extranjero que se pretende acreditar. Lo que significa que no es suficiente en modo alguno una simple cita aislada de disposiciones extranjeras, pues ello no prueba nada en cuanto al contenido literal de la norma extranjera. ${ }^{67} \mathrm{Y}$ por derecho extranjero, como se ha indicado, ha de entenderse la totalidad del ordenamiento jurídico foráneo, que comprende todo tipo de normas jurídicas que lo integren y que pudieran ser aplicables al supuesto en concreto. También se incluiría la acreditación literal de las normas de conflicto extranjeras en el caso de que pudieran dar lugar al reenvío o de que alguna parte mantuviera la no existencia de reenvío. ${ }^{68}$

b) Debe acreditarse también la "vigencia" y existencia del derecho extranjero. Se trata de una cuestión que a veces no resulta fácil, en particular cuando nos encontramos ante supuestos de Estados de reciente creación o en supuestos en los que, por ejemplo, exista una posible contradicción entre las leyes de un país y la Constitución de dicho país. ${ }^{69}$

65 Respecto a la aplicación de la tesis de la necesidad de una amplia prueba del derecho extranjero, más allá de la mera acreditación de su contenido y vigencia - tesis de la prueba exhaustiva-, véanse, entre otras, las sentencias del Tribunal Supremo del 12 de mayo de 1987; 13 de enero de 1987; 11 de mayo de 1989; 12 de enero de 1989; 7 de septiembre de 1990; 16 de julio de 1991; 23 de octubre de 1992; 15 de noviembre de 1996; 25 de enero de 1999; 17 de julio de 2001; 4 de julio de 2006 o 17 de abril de 2015. Un atinado resumen de la referida jurisprudencia, véase en Fernández Rozas, José Carlos y Sánchez Lorenzo, Sixto, Derecho internacional privado, 9a. ed., Cizur Menor, Aranzadi, 2016, pp. 185 y 186.

66 Garau Sobrino, Federico, op. cit., p. 5.

67 En tal sentido, sentencia de la Audiencia Provincial de Baleares del 27 de abril de 2006.

68 Así, sentencia del Tribunal Supremo del 15 de noviembre de 1996, de la Audiencia Provincial de Tarragona, del 13 de mayo de 2004 o de la Audiencia Provincial de Madrid del 22 de diciembre de 2008.

69 Fue el caso resuelto por la sentencia del Tribunal Superior de Justicia de Madrid del 14 de marzo de 2012, en el caso de una reclamación formulada por un trabajador de nacionalidad italiana al servicio de la administración española.

Esta obra está bajo una Licencia Creative Commons

Atribución-NoComercial-SinDerivar 4.0 Internacional, IIJ-UNAM.

Boletín Mexicano de Derecho Comparado, núm. 150, pp. 1351-1394 
c) En tercer lugar ha de acreditarse, asimismo, la "interpretación" que la jurisprudencia extranjera hace de la concreta norma del derecho extranjero que se pretende probar; ${ }^{70}$ es decir, ha de acreditarse cómo es aplicada tal norma por los tribunales en el Estado de origen de la misma, y para ello quizá la prueba pericial resulte la más idónea — infra-

d) Finalmente, debe quedar clara la "aplicabilidad" del derecho extranjero al supuesto en cuestión, de manera que una vez probado el contenido, vigencia e interpretación del derecho extranjero no se suscite la menor duda razonable al respecto al tribunal español. ${ }^{71}$

\section{B. Los medios de prueba del derecho extranjero}

Sentado lo que ha de constituir el objeto de la prueba del derecho extranjero, sin embargo, el artículo 281 de La Ley de Enjuiciamiento Civil y el artículo 33 de la LCJIMC guardan silencio sobre los concretos medios que pueden ser utilizados para la prueba del contenido, vigencia e interpretación del derecho extranjero. Ante la falta de previsión específica habrán de ser utilizados los medios contemplados con carácter general en el artículo 299.1 de la Ley de Enjuiciamiento Civil. No existe una lista cerrada de medios apropiados para acreditar el derecho extranjero, si bien los mecanismos de prueba más apropiados de los recogidos en la citada Ley serían los documentos públicos (artículo 317), los documentos privados (artículo 324), el dictamen pericial (artículo 335) y la declaración de un testigo-perito (artículo 370.4).

Dejamos ahora al margen los medios de prueba de los que puede valerse el tribunal para la acreditación del derecho extranjero, esto es, vamos a tratar exclusivamente los medios que las partes pueden utilizar con más éxito para su acreditación. ${ }^{72} \mathrm{Y}$ hemos de reiterar que actualmente

70 Así lo ha exigido el Tribunal Supremo en una clásica y reiterada jurisprudencia, entre otras muchas sentencias del 13 de enero de 1987; 10 de julio de 2000; 12 de julio de 2004; 30 de junio de 1962; 12 de enero de 1989; 7 de septiembre de 1990; 16 de julio de 1991 y 25 de enero de 1999.

71 Es un requisito impuesto por el Tribunal Supremo: sentencias del 25 de enero de 1999 o 17 de julio de 2001.

72 Hoy se ha superado la clásica jurisprudencia del Tribunal Supremo que requería para probar el derecho extranjero una prueba cumulativa documental y pericial (así, entre otras muchas, sentencias del 28 de octubre de 1968; de 6 de junio de 1969; de 5 de noviem- 
cualquier medio de prueba es válido, en principio, para probar el derecho extranjero, siempre que éste sea acreditado con certeza; esto es, que al tribunal no lo quede duda razonable de la procedencia de su aplicación al caso. ${ }^{73}$

\section{a. Documentos públicos}

Los documentos públicos que se suelen utilizar son certificaciones expedidas por la Subdirección General de Cooperación Jurídica internacional del Ministerio de Justicia español del contenido del derecho extranjero (aunque éstas sólo pueden ser solicitadas por el tribunal); certificaciones expedidas por funcionarios diplomáticos extranjeros acreditados en España, las cuales deben ser presentadas legalizadas y traducidas al español (artículos 323.3 y 144, respectivamente, de la Ley de Enjuiciamiento Civil); o certificaciones expedidas por funcionarios diplomáticos o consulares españoles acreditados en el Estado cuyo derecho se pretende probar. ${ }^{74}$ Normalmente a través de la prueba documental pública lo que se trata de probar es el contenido del derecho extranjero mediante la transcripción literal de los preceptos alegados - lo cual también se puede hacer mediante la documental privada-, así como su vigencia a través de la diligencia de la autoridad emisora sobre tal aspecto recogida en el propio documento.

bre de 1971; de 12 de marzo de 1972; de 3 de febrero de 1975 o de 12 de noviembre de 1976). Desde que entró en vigor la actual Ley de Enjuiciamiento Civil es frecuente encontrarnos con supuestos donde la acreditación del derecho extranjero tiene lugar mediante la práctica de una sola prueba, normalmente documental o pericial (así, sentencia de la Audiencia Provincial de Alicante del 27 de febrero de 2004; de la Audiencia Provincial de Baleares del 31 de marzo de 2004 o de la Audiencia Provincial de Tenerife del 9 de diciembre de 2009).

73 Un estudio más detallado de los distintos medios de pruebas utilizables por las partes para la acreditación del contenido, vigencia e interpretación del derecho extranjero, así como sobre el momento procesal oportuno a tal efecto, véase Garau Sobrino, Federico, op. cit., pp. 2352-2356.

74 Ha de significarse que carecen de valor de documento público, las fotocopias de normas aisladas extranjeras y las traducciones privadas de textos legales extranjeros, por lo cual, en principio no permiten de por sí acreditar el contenido y vigencia del derecho extranjero. Para un análisis más extenso sobre los documentos públicos extranjeros y los problemas que platean como medio de prueba del derecho extranjero, véase Garcimartín Alférez, Francisco José, Derecho internacional privado..., cit., pp. 234-236.

Esta obra está bajo una Licencia Creative Commons

Atribución-NoComercial-SinDerivar 4.0 Internacional, IIJ-UNAM.

Boletín Mexicano de Derecho Comparado, núm. 150, pp. 1351-1394 


\section{b. Documentos privados}

La acreditación del derecho extranjero puede llevarse a cabo también mediante documentos privados (por ejemplo, una obra doctrinal, una colección de leyes, etcétera) y su valoración será apreciada en cada caso libremente por el juez atendiendo a las circunstancias que concurran y a la regla de la sana crítica. En todo caso, no es éste el medio más fiable para la acreditación del derecho extranjero, aunque pueda ser útil en determinados casos que no presenten excesiva complejidad, si bien lo aconsejable es que el documento privado se aporte junto a algún documento público o dictamen pericial, esto es, como complemento de los mismos.

\section{c. Prueba pericial}

Es uno de los medios tradicionalmente más utilizados para la prueba del derecho extranjero. Normalmente son informes redactados por expertos jurídicos del país cuyo derecho se pretende acreditar, pero ello no es requisito para admitir su validez. Los dictámenes suelen ser realizados por abogados en ejercicio, por académicos o por cualquier otro experto en el sector del derecho extranjero que se pretende probar ante el tribunal español. El dictamen pericial quizá sea el medio de prueba más adecuado en cuanto que a través del mismo se puede acreditar tanto el contenido como la vigencia del derecho extranjero, pero también sobre todo, su interpretación y adecuación al caso concreto, aspecto que difícilmente se puede probar a través de la prueba documental.

$\mathrm{Al}$ margen de la prueba pericial, nos encontraríamos ante uno de los supuestos donde pudiera utilizarse la figura del testigo-perito contemplada en el artículo 470.4 de la Ley de Enjuiciamiento Civil, siempre y cuando concurriera la condición de testigo y de experto en la persona del declarante, lo cual no es fácil que acontezca.

\section{El papel del juez ante la prueba del derecho extranjero}

La función que debe desempeñar el juez en el proceso de prueba del derecho extranjero se ha visto tradicionalmente condicionada por la consideración jurídica que se tenga del derecho extranjero: si éste es consi- 
derado como un simple "hecho", la carga de la prueba del mismo debe recaer en las partes, y el juez jugará un papel pasivo; por el contrario, si se estima que estamos ante un auténtico "derecho", la intervención más activa del juez se podría entender justificada por encontrarnos ante una obligación derivada de la regla iura novit curia. ${ }^{75}$

El artículo 281 de la Ley de Enjuiciamiento Civil diferencia claramente entre la prueba de los "hechos", por una parte, y la prueba de la costumbre y del "derecho extranjero", por otra. Sin embargo, el referido precepto no deja lugar a la duda de que tal derecho "deberá ser probado en cuanto a su contenido y vigencia"; y, con relación a esa prueba, del nuevo artículo 33.3 de la LCJIMC se deduce claramente que, en principio, la prueba de dicho derecho corresponde con carácter general "a las partes". Y ello frente a lo dispuesto en el artículo 281.2 de la Ley de Enjuiciamiento Civil, donde únicamente se establece que el derecho extranjero debe ser probado en cuanto a su contenido y vigencia, pero sin hacerse referencia expresa alguna a "las partes", como los obligados a realizar dicha prueba, aunque después la doctrina y jurisprudencia hayan sido unánimes en considerar que dicha obligación recae sobre éstas. ${ }^{76}$

Así las cosas, el derecho extranjero recibe un tratamiento "híbrido" en nuestro ordenamiento, ${ }^{77} \mathrm{y}$ en cuanto que aunque parece que el legislador le otorgue en principio la misma consideración por lo que respecta a su prueba que el establecido para los hechos, lo cierto es que nos encontramos ante

75 No obstante, dudamos que este principio alcance al derecho extranjero, pues no se puede exigir a los jueces de un país que conozcan el derecho de otro Estado. En contra, ,Miralles Sangro, Pedro Pablo, para quien a la norma extranjera - y teniendo en cuenta el tratamiento procesal sui generis que ha de darse al derecho extranjero como "hecho"- le debería ser aplicable el referido principio, convirtiéndose precisamente ello en el eje central de la tutela judicial efectiva con relación a la aplicación del derecho extranjero en el proceso (Aplicación del derecho extranjero en el proceso y tutela judicial, cit., pp. 205-209).

76 Siendo la regla general, la necesidad de probar el derecho extranjero cada vez que deba aplicarse; sin embargo, existen algunas excepciones a ello: así, en los casos en los que el tribunal ya sea conocedor del mismo (por ejemplo, por ya haberlo aplicado en procesos anteriores y conocerlo de modo indubitado) o en casos en que la información necesaria para que su aplicación sea de público conocimiento y acceso (ordenamientos extranjeros contenidos en páginas webs oficiales accesibles para todos - sentencia de la Audiencia Provincial de Santa Cruz de Tenerife del 15 de julio de 2014, respecto del derecho alemán-).

77 José Carlos Fernández Rozas y Sixto Sánchez Lorenzo mantienen que el derecho extranjero tiene una consideración procesal "peculiar", viniendo a ser un tertium genus entre el derecho y los hechos (Derecho internacional privado, cit., p. 173).

Esta obra está bajo una Licencia Creative Commons

Atribución-NoComercial-SinDerivar 4.0 Internacional, IIJ-UNAM.

Boletín Mexicano de Derecho Comparado, núm. 150, pp. 1351-1394 
un derecho, si bien extranjero. ${ }^{78}$ En tal sentido se habla de la existencia en nuestro sistema de un "modelo mixto" de colaboración entre el tribunal y las partes para la acreditación del derecho extranjero. ${ }^{79} \mathrm{Y}$ es en este marco en el que se plantea la cuestión relativa al papel — más o menos activoque debe jugar el juez respecto a la prueba de tal derecho. ${ }^{80}$

78 Carrillo Salcedo, Juan Antonio, Derecho internacional privado, 3a. ed., Madrid, Tecnos, 1983, p. 257. Lo que no parece discutible es que el derecho extranjero es derecho, y es el que en su caso deberá resolver el fondo del asunto sometido a litigio, por lo que ha de acreditarse su contenido y vigencia (Calvo Caravaca, Alfonso Luis y Carrascosa González, Javier, Derecho ..., cit. (16a. ed.), pp. 532 y 533).

79 Quizá este modelo mixto de prueba del derecho extranjero sea en la actualidad el que mejor garantice su aplicación, habiendo sido el adoptado, con matices, en la mayor parte de los Estados, sobre todo en los que disponen de una ley especial de derecho internacional privado: así, artículo 14 de la Ley italiana de derecho internacional privado del 31 de mayo de 1995; artículo 15 del Código belga de derecho internacional privado del 16 de julio de 2004 o artículo 16 de la Ley suiza de derecho internacional privado del 18 de diciembre de 1987 . Y es clarificador al efecto que en el preámbulo de la LGJIMG se establezca que "(n)uestro sistema se caracteriza por ser un sistema mixto que combina el principio de alegación y prueba a instancia de parte con la posibilidad de que el tribunal complete dicha prueba, valiéndose de cuantos medios de averiguación estime necesarios". La doctrina también se ha mostrado favorable al modelo en cuestión, así Aguilar Benítez de Lugo, Mariano, "La prueba del derecho extranjero ante los tribunales españoles", Revista General del Derecho, núm. 541-542, 1989, pp. 6247-6314; Maseda Rodríguez, Javier, "La aplicación judicial del derecho extranjero: el nuevo régimen de la LEG y la reciente jurisprudencia constitucional", Actualidad Civil, núm. 12, 2002, pp. 420-430; y Gutiérrez de Cabiedes, Eduardo, "Tratamiento procesal del derecho extranjero en el título preliminar del Código civil", Anuario de Derecho Internacional, vol. II, 1975, pp. 62 y 63.

80 Debe indicarse que por desgracia la jurisprudencia constitucional en relación con el papel que debe desempeñar el juez ante la prueba del derecho extranjero es poco aclaradora, no resultando de ella una posición genérica sobre la cuestión: no se recoge un deber del juez de colaborar con las partes en la acreditación del derecho extranjero, a salvo del supuesto en que la parte obligada a la prueba hubiera actuado con acreditada diligencia, en cuyo caso la "colaboración" por parte del juez debe ser exigible (sentencias del Tribunal Constitucional 10/2000, del 17 de enero de 2000; 155/2001, del 2 de julio de 2001; 33/2002, del 11 de febrero de 2001 y 172/2004, del 18 de octubre de 2004). Sobre la jurisprudencia del Tribunal Constitucional en relación con la prueba del derecho extranjero, véase, entre otros, Álvarez González, Santiago, "La aplicación judicial del derecho extranjero bajo la lupa constitucional", Revista Española de Derecho Internacional, 2002, núm. 1, pp. 205-223; Maseda Rodríguez, Javier, "La aplicación judicial del derecho extranjero: el nuevo régimen de la LEG y la reciente jurisprudencia constitucional", cit., pp. 414-418; Carrillo Pozo, Luis, "Una doctrina constitucional sobre alegación y prueba de la Ley extranjera", Aranzadi Social, 2003, núm. 7-8, pp. 53-84; Cuarteto Rubio, Victoria, "Prueba del derecho extranjero y tutela judicial efectiva", Derecho Privado y Constitución, 
Con relación al deber de colaboración del juez con las partes para la averiguación del contenido y vigencia del derecho extranjero, nos encontraríamos ante una vulneración del artículo 24.2 de la Constitución en dos supuestos: a) por un lado, y dado que el derecho a la prueba consiste en que las pruebas pertinentes sean admitidas y practicadas (sentencias del Tribunal Constitucional 181/1995, del 11 de diciembre, 246/1994, del 19 de diciembre y 1/1992, del 13 de enero), en el caso de que el tribunal no admitiera pruebas que fueran pertinentes o, que de haberlas admitido, no fueran practicadas (sentencias del Tribunal Constitucional 246/1994, del 19 de diciembre y 50/1988, del 22 de marzo), y b) por otro, en el caso de que habiendo una parte fundado debidamente sus pretensiones en un derecho extranjero y actuando con diligencia en la averiguación de su vigencia y contenido, el juez denegara las pretensiones de la parte por la no prueba del derecho extranjero cuando dicha deficiencia es resultado directo de la no colaboración del juez de manera injustificada (sentencia del Tribunal Constitucional 155/2001, del 2 de julio).

Desde la perspectiva puramente procesal, cuando el artículo 281.2 de la Ley de Enjuiciamiento Civil establece que, en relación con la prueba del derecho extranjero, el tribunal (en los términos referidos) puede valerse de cuantos medios de averiguación estime necesarios para su aplicación, la propia norma procesal pone a su disposición momentos procesales e instrumentos suficientes para hacer valer dicha posibilidad. Así, en la audiencia previa en el procedimiento ordinario, si considera que las pruebas propuestas pueden ser insuficientes, el juez tiene la facultad de advertirlo y señalar a las partes la prueba o pruebas que considere más apropiadas (artículo 429.1.III); o en el trámite de diligencia finales puede el juez adoptar, mediante auto, la práctica de determinadas actuaciones probatorias que pueden afectar a la acreditación del derecho extranjero (artículo 435); en el juicio verbal, el juez tiene la facultad de indicar a las

núm. 14, 2000, pp. 21-71; Desdentado Bonete, Aurelio, “¿Otro cierre en falso? La prueba del derecho extranjero", Diario La Ley, núm. 6188, 11 de febrero de 2005, pp. 1 y 2, y Calvo Caravaca, Alfonso Luis y Carrascosa González, Javier, "El Tribunal Constitucional y el Tribunal Supremo ante la falta de alegación y prueba del derecho extranjero (en torno a la sentencia, social, del 4 de noviembre de 2004)", Diario La Ley, núm. 6238, 25 de abril de 2005, pp. 1-11.

Esta obra está bajo una Licencia Creative Commons

Atribución-NoComercial-SinDerivar 4.0 Internacional, IIJ-UNAM.

Boletín Mexicano de Derecho Comparado, núm. 150, pp. 1351-1394 
partes la práctica de determinadas pruebas, también exartículo 429.1; por último, en los procesos especiales se permite al juez adoptar cuantos medios de prueba estime pertinentes, y ello con independencia de los solicitados por el Ministerio Fiscal o las partes (artículo 752.1.II). ${ }^{82}$

\section{Valoración de la prueba según las "reglas de la sana crítica"}

Una vez finalizada la actividad probatoria, corresponderá a los tribunales determinar el valor probatorio de la prueba practicada de acuerdo con las "reglas de la sana crítica", noción establecida de manera novedosa en el artículo 33.2 de la LCJIMC, y que conforma una categoría intermedia entre la prueba legal y la libre convicción del juez. ${ }^{83}$ Los medios de acreditación del derecho extranjero serán libremente apreciados por el tribunal, quien realizará una valoración sobre la fuerza probatoria de los diferentes medios de prueba empleados con arreglo a la citada regla. Ello significa que en este ámbito no opera un sistema de prueba tasada, no encontrándose el tribunal vinculado por las pruebas practicadas.

Redundando en la valoración conforme a las reglas de la sana crítica, ha de tenerse en cuenta que a tenor del artículo 33.4 de la LCJIMC: "(n)ingún informe o dictamen, nacional o internacional, sobre Derecho extranjero, tendrá carácter vinculante para los órganos jurisdiccionales

81 En efecto, como indica Federico Garau Sobrino, mientras las diligencias finales, previstas únicamente para el juicio ordinario, no son aplicables para el juicio verbal (artículo 445); sin embargo, el artículo 429.1 —incluido dentro de la regulación del juicio ordinario - sí es aplicable al juicio verbal a tenor del artículo 443.4, p. 2 (op. cit., p. 2348).

82 Con relación al momento procesal en el que, en los distintos procedimientos, el juez puede llevar a cabo actuaciones en aras a la acreditación del derecho extranjero, véase Garau Sobrino, Federico, op. cit., pp. 2346-2352.

83 Referente a la regla de la sana crítica, véase, entre otros, Taruffo, Michele, La prueba de los hechos, trad. de Jordi Ferrer Beltrán, Madrid, Trotta, 2002; Seoane Spielgeber, José Luis, La prueba en la Ley de Enjuiciamiento Civil 1/2000. Disposiciones generales y presunciones, 2a. ed., Cizur Menor, Aranzadi, 2007; Lazo Cordero, Jaime, "Lógica y sana crítica", Revista Chilena del Derecho, vol. 36, núm. 1, 2009, pp. 143-164 y Zubiri de Salinas, Fernando, “¿Qué es la sana crítica? La valoración judicial del dictamen experto", Fueces para la Democracia, Información y Debate, núm. 50, julio de 2004, pp. 55 y 56. En cuanto al tratamiento de la regla de la sana crítica en la jurisprudencia, véanse sentencias del Tribunal Supremo del 19 febrero 2007; del 17 de octubre de 2006 y del 19 de diciembre de 2005; sentencia de la Audiencia Provincial de Madrid del 28 noviembre 2006 o de la Audiencia Provincial de Guipúzcoa del 15 mayo de 2006. 
españoles"; es decir, ni siquiera estos medios probatorios - que en principio pudieran presentarse como idóneos para la acreditación del derecho extranjero - presentan un carácter vinculante para el tribunal, sino que deberá valorarlos y decidir si con fundamento en el contenido de los mismos puede resolverse aplicando el derecho extranjero sin ofrecerle dudas en el sentido que se mantenga en el informe o dictamen en cuestión.

Respecto a los documentos públicos, el hecho de que el artículo 319.1 de la Ley de Enjuiciamiento Civil se refiera a la "prueba plena" que en principio se predica de los mismos, no significa que la afirmación que realice un funcionario público extranjero sobre el derecho extranjero en un documento público deba ser tenida por cierta en todo caso. Lo que quiere decir es que la opinión recogida en tal documento no ha de ser puesta en duda en cuanto su veracidad y autenticidad; es decir, lo que se recoge en informes contenidos en un documento público con relación al derecho extranjero no puede ser puesto en duda en cuanto que hace prueba plena del hecho, acto o estado de cosas que se documenten, de la fecha y de la identidad de las personas que intervienen en el mismo. ${ }^{84}$ Sin embargo, la valoración de la fuerza probatoria de lo dispuesto en el documento en cuanto a su contenido no deja de estar sometida a la regla de la sana crítica.

Para finalizar este punto, en el hipotético supuesto de que una parte presente una prueba sobre el derecho extranjero y la otra parte no la impugne, ello no ha de implicar que se acepte automáticamente por el tribunal el contenido y vigencia del tal derecho, pues éste deberá decidir si dicha prueba es suficiente o no para causar tal efecto. ${ }^{85}$ En este sentido, no se debe aceptar la prueba del derecho extranjero mediante la doctrina de los hechos admitidos, dado que dicha doctrina sólo es aplicable respecto a

84 De la eficacia material de los documentos públicos extranjeros mantiene Francisco José Gacimartín Alférez, que la misma "viene determinada por la lex causae (artículo 323.3, LEG). El contenido de esos documentos se lee desde la lex causae y, en consecuencia, esta ley determina, por ejemplo, la necesidad de esos documentos como requisito de validez del negocio o de la producción de determinados efectos sustantivos" (Derecho internacional privado..., cit., p. 236).

85 Sobre el particular véase sentencia de la Audiencia Provincial de Santa Cruz de Tenerife del 24 de marzo de 2006.

Esta obra está bajo una Licencia Creative Commons

Atribución-NoComercial-SinDerivar 4.0 Internacional, IIJ-UNAM.

Boletín Mexicano de Derecho Comparado, núm. 150, pp. 1351-1394 
los hechos (artículo 281.3 de la Ley de Enjuiciamiento Civil). ${ }^{86}$ En definitiva, para que el tribunal aplique un derecho extranjero previamente ha de haberse acreditado que lo que se va a aplicar es un derecho extranjero, y no es de recibo que ello tenga lugar por un mero acuerdo entre las partes (STS del 5 de noviembre de 1971). ${ }^{87}$

\section{La aplicación de la ley española en caso de no acreditación por las partes del contenido y vigencia del derecho extranjero}

Sin duda, una de las novedades más interesantes que aporta el artículo 33 de la LCJIMC es la que se encuentra en su apartado tercero cuando establece que "con carácter excepcional, en aquellos supuestos en los que no haya podido acreditarse por las partes el contenido y vigencia del Derecho extranjero, podrá aplicarse el Derecho español".

Los supuestos en los cuales resulte que no se acredite el derecho extranjero pueden ser muy variados, siendo divididos por la doctrina en dos bloques: a) desde los casos de actitudes pasivas o poco diligentes de las partes en las que no plantean la aplicación del derecho extranjero - siendo aplicable según nuestras norma de conflicto - y, aun invocándolo, no realizan una actividad seria o mínimamente diligente en aras a su prueba, y b) hasta los supuestos más extremos en los que resulta materialmente imposible la prueba del derecho extranjero (casos de países en conflictos bélicos, o países de reciente creación sin un ordenamiento conocido, o en los que la prueba del derecho extranjero comporta un coste excesivo o exorbitante, etcétera). ${ }^{88}$

86 Respecto a la posibilidad de aplicar a la prueba del derecho extranjero, la teoría relativa a la prueba de los "hechos notorios", los cuales están exentos de prueba conforme a la regla notoria non egent probatione, véase Miralles Sangro, Pedro Pablo, Aplicación del derecho extranjero en el proceso y tutela judicial, cit., pp. 191-195.

${ }^{87} \mathrm{Y}$ en el caso de que las partes presenten pruebas contradictorias acerca del derecho extranjero (por ejemplo, sendos dictámenes de barristers irlandeses sobre el contenido, vigencia e interpretación del derecho irlandés - SAP Barcelona del 15 de enero de 2014-), el tribunal decidirá el medio de acreditación que le resulte más fiable y, en caso de duda insoluble, tendrá por no probado el derecho extranjero, con las consecuencias que procedan (Calvo Caravaca, Alfonso Luis y Carrascosa González, Javier, Derecho..., cit. (16a. ed.), pp. 548 y 549$)$.

88 Véase al respecto la obra citada en la nota anterior, pp. 567-581. En relación con el desconocimiento del derecho extranjero por parte del tribunal, y, por lo tanto, su imposibi- 
1. Con relación al primer bloque de supuestos, se proponen como posibles soluciones las siguientes.

a) En primer término, la aplicación de oficio por parte del juez del derecho extranjero. Tesis contraria a la ley, como hemos indicado, en nuestro sistema de derecho internacional privado, salvo supuestos excepcionales, son las partes las que deben acreditar el derecho extranjero. ${ }^{89}$

b) En segundo lugar, la aplicación sustitutiva del derecho material español. Tesis avalada por la jurisprudencia del Tribunal Supremo desde el siglo XIX, ${ }^{90}$ si bien hoy en día se encuentra en entredicho y encontramos resoluciones del Tribunal Supremo en un sentido contrario a la misma. ${ }^{91}$ Se trata de una tesis que, aplicada con carácter general, a nuestro entender vulnera el carácter imperativo de la norma de conflicto (artículo 12.6 del Código Civil), comporta una gran inseguridad jurídica y da lugar a

lidad de aplicación, Francisco José Garcimartín Alférez plantea tres posibles supuestos: en primer término, la "indeterminación en sentido débil", donde el juez conoce el enunciado normativo; no obstante, tiene dudas sobre su validez o interpretación; en segundo lugar, sitúa al "conocimiento incompleto", que se produce cuando el juez ignora algún aspecto esencial para la aplicación del derecho extranjero: el enunciado normativo, la interpretación o las obras doctrinales; finalmente, la "indeterminación en sentido fuerte", la cual tiene lugar cuando una vez agotados los medios de investigación judicial del derecho extranjero,l, Madrid, Tecnos, 1994, pp. 60-66).

89 Esta tesis que no respeta el reparto de la carga de la prueba establecido en el artículo 282 de la Ley de Enjuiciamiento Civil, tampoco cuenta con el apoyo favorable de la jurisprudencia (sentencias del Tribunal Supremo del 31 de diciembre de 1994 o del 10 de junio de 2005).

90 Así, entre otras muchas, las sentencias del Tribunal Supremo del 22 de julio de 2009; 30 de abril de 2008; 27 de diciembre de 2006; 10 de junio de 2005; 2 de julio de 2004; 29 de diciembre de 2003; 5 de marzo de 2002; 17 de julio de 2001; 13 de diciembre de 2000 o 5 de junio de 2000. Por su parte, el Tribunal Constitucional nunca ha afirmado que esta tesis sea la única que encaje con la tutela judicial efectiva ante la falta de prueba del derecho extranjero (sobre la tibia posición del Tribunal Constitucional en esta materia véase nota 81).

91 Así, en particular, la sentencia del Tribunal Supremo del 18 de octubre de 2010, que en un supuesto de aplicación del derecho argentino estableció que cuando la demanda o reconvención no va acompañada de la correspondiente prueba del contenido y vigencia del derecho extranjero procede su desestimación "por cuanto se trata de un hecho constitutivo". Esta última también fue la tesis defendida por la Sala Cuarta del Tribunal Supremo entre 2001 y 2004 (sentencia del 22 de mayo de 2001, entre otras), hasta que la misma fue rechazada mediante sentencia de la Sala Cuarta del 4 de noviembre de 2004, dictada en unificación de la doctrina; desde entonces la Sala Cuarta del Tribunal Supremo mantiene que: "acata la doctrina, pero no la comparte".

Esta obra está bajo una Licencia Creative Commons

Atribución-NoComercial-SinDerivar 4.0 Internacional, IIJ-UNAM.

Boletín Mexicano de Derecho Comparado, núm. 150, pp. 1351-1394 
maniobras evasivas de la ley por parte de litigantes proclives a actuar de mala fe. ${ }^{92}$

c) Finalmente, la desestimación de la demanda. Se trata quizá de la solución, al menos desde un punto de vista dogmático, más correcta. Los argumentos a su favor son múltiples, ${ }^{93} \mathrm{y}$, como hemos apuntado, ha sido la tesis mantenida por la Sala Cuarta del Tribunal Supremo hasta que la misma fue rechazada mediante sentencia del 4 de noviembre de 2004, dictada en unificación de doctrina. Además, interpretado a contrario sensu, parece la tesis más procedente a la vista de lo dispuesto en el artículo 33.3 de la LCJIMC, pues en el mismo sólo se prevé la aplicación sustitutiva del derecho español en supuestos excepcionales (que no son los que ahora abordamos), por lo que, al menos en principio, cabe prever que sea posible la desestimación de la demanda en otros casos. ${ }^{94}$

2. Por el contrario, con relación al referido segundo bloque de supuestos de imposibilidad de prueba del derecho extranjero, aquellos donde existe una imposibilidad real y manifiesta de acreditar el derecho extranjero - no concurriendo ánimo especulativo alguno por las partes-, en principio habría que diferenciar si la norma de conflicto que nos ha remitido a tal derecho tiene un único punto de conexión o varias conexiones sucesivas en su aplicación: ${ }^{95}$

92 Federico Garau Sobrino señala al respecto que “...está claro que el Derecho positivo español parte del principio de indisponibilidad de las normas de conflicto"; esta claridad quedó más de manifiesto, si cabía, cuando se derogó el párrafo segundo del artículo 12.6 del Código Civil y se dejó inalterado el párrafo primero, de donde se dedujo "una clara intención del legislador de seguir manteniendo el principio de un Derecho internacional privado imperativo". (Op. cit., p. 2345).

93 Puede verse un profundo análisis de los mismos en Calvo Caravaca, Alfonso Luis y Carrascosa González, Javier, Derecho..., cit. (16a. ed.), pp. 573-576.

94 En relación con el ajuste constitucional de la desestimación de la demanda en casos de no prueba del derecho extranjero, véase Maseda Rodríguez, Javier, "La aplicación judicial del derecho extranjero: el nuevo régimen de la LEC y la reciente jurisprudencia constitucional", cit., pp. 430-444.

95 En estos supuestos de indeterminación del derecho extranjero, "en sentido fuerte", la doctrina mantiene que no cabe la desestimación de la demanda como solución posible, pues, entre otros motivos - quedaría en entredicho el carácter jurídico del derecho extranjero, supondría la imposición total de la carga de la prueba a las partes, etcétera- y se incurriría en una situación de inadmisible denegación de justicia contraria al artículo 24 de la Constitución. En estos casos, la aplicación sustitutiva de la lex fori impide males mayores que la transgresión de la imperatividad de las normas de conflicto recogida en el 
a) Si la norma tuviera sólo un punto de conexión y el derecho declarado aplicable no podría ser acreditado, entonces la única solución rigurosa que se ofrece es la aplicación de la ley del Estado del foro, en nuestro caso, la ley española.

b) Si por el contrario la norma de conflicto dispusiera de más de una conexión, habría que acudir al derecho al cual nos condujera la aplicación de la segunda conexión (o, en su caso, la tercera o siguientes, hasta conseguir un derecho aplicable).

Pues bien, en este contexto de posibles supuestos con relación a la carencia de prueba del derecho extranjero, nos encontramos con el novedoso artículo 33.3 de la LGJIMC, y aunque la solución no sea todo clara y segura, nuestro legislador parece haberse decantado, si bien con matices, por la tesis de la aplicación sustitutiva del derecho español. ${ }^{96} \mathrm{La}$ norma, que presenta varias lagunas ${ }^{97}$ además resultará compleja en su aplicación..$^{98}$

a) En primer término, no se establece qué ocurre en los casos en los que no haya sido probado el contenido y vigencia del derecho extranjero por las partes (por falta de diligencia, por ejemplo) y el juez no estime que concurra la "excepcionalidad" exigida; en tal supuesto entendemos que se seguirán planteando otras posibles soluciones, como la desestimación de la demanda o la aplicación del derecho al cual conduzca la posterior conexión (si la hubiera). Es decir, los casos en los que no exista "excepcionalidad" continuarán siendo supuestos huérfanos de regulación legal. El artículo 33.3 sólo ofrece soluciones para los supuestos en los que real-

artíulo 12.6 del Código Civil (véase Garcimartín Alférez, Francisco José, Sobre la norma de conflicto y su aplicación judicial..., cit., pp. 67-69).

96 Sobre la regulación contenida en el nuevo artículo 33.3 de la LCJIMC, véase Ybarra Bores, Alfonso, en Rodríguez Benot, Andrés et al., Manual de derecho internacional privado, 3a. ed., Madrid, Tecnos, 2016, pp. 164 y 165.

97 Como ya adelantamos, se trata de una solución que no concuerda muy bien con algunas normas de nuestro sistema, especiales y aun contradictorias entre sí (ver nota 57).

98 Para un análisis profundo acerca de los motivos de crítica al artículo 33.3 de la LCJIMC, véase Calvo Caravaca, Alfonso Luis, "La aplicación judicial del derecho extranjero en España. Consideraciones críticas", Revista Española de Derecho Internacional, cit., pp. 147 154.

Esta obra está bajo una Licencia Creative Commons

Atribución-NoComercial-SinDerivar 4.0 Internacional, IIJ-UNAM.

Boletín Mexicano de Derecho Comparado, núm. 150, pp. 1351-1394 
mente resulte materialmente imposible para las partes probar el derecho extranjero, ${ }^{99}$ incluso con la posible ayuda del tribunal. ${ }^{100}$

b) Seguidamente, se trata de una norma de carácter nacionalista y legeforista, que ha desconocido otras posibles soluciones que se barajaban por la doctrina, como la aplicación de la conexión subsidiaria de la norma de conflicto (si existiera) en el supuesto de que el derecho designado por la primera conexión fuera de imposible acreditación. ${ }^{101}$ Sin embargo, en el artículo 33.3 se ha optado como solución, acudir directamente a la aplicación sustitutiva del derecho español. ${ }^{102}$

$99 \mathrm{Al}$ respecto, Francisco José Garcimartín Alférez mantiene que "la aplicación de esta solución es enormemente problemática pues constituye casi una prueba diabólica o de hechos negativos: ¿cómo se demuestra que no se ha podido acreditar el contenido de la ley extranjera? El cumplimiento de esta carga no debe apreciarlo de oficio el juez, sino la parte interesada" (Derecho internacional privado..., cit., p. 240).

100 Además, al tratarse de una norma prevista exclusivamente para casos excepcionales de prueba imposible del derecho extranjero no puede ser aplicada analógicamente, por lo que no podrá utilizarse para fundamentar sobre la misma la aplicación del derecho español en aquellos supuestos en que, por ejemplo, las partes, pudiendo haber probado el derecho extranjero, no hubieran querido hacerlo.

101 Así, Francisco José Garcimartín Alférez, ante la laguna legal tradicionalmente existente en nuestro sistema de derecho internacional privado, se refería a las soluciones ofrecidas por la doctrina: bien la aplicación subsidiaria de la lex fori, bien la aplicación de un derecho "pariente" o "cercano", bien la aplicación de unos principios generales del derecho deducidos de un estudio de derecho comparado o la aplicación de un derecho uniforme. No obstante, esas soluciones eran criticadas por el referido autor, quien mantuvo que la solución debía pasar por respetar los postulados del sistema conflictual y adaptarse a cada tipo de remisión: así abogaba por la utilización de criterios de conexión subsidiarios deducidos del propio sistema de derecho internacional privado y, sólo en el caso de que esta solución resultara infructuosa, se debería acudir a la aplicación de la lex fori como ultima ratio (Sobre la norma de conflicto y su aplicación judicial..., cit., pp. 69-72).

$102 \mathrm{Al}$ margen de ello, como se ha reiterado, es una solución prevista sólo para supuestos "excepcionales", que en la práctica acontecen en muy raras ocasiones, no existiendo apenas casos en la jurisprudencia española en los que la prueba del derecho extranjero - incluso con la colaboración del tribunal - sea materialmente imposible. Por ello, el artículo 33.3 puede ser considerado como una norma carente de sentido desde un punto de vista práctico, y máxime si tenemos en cuenta que son mucho más numerosos los supuestos en los que la inaplicación del derecho extranjero viene dada por una actitud pasiva o poco diligente de las partes, supuestos que, como hemos indicado, siguen sin tener una regulación en nuestro sistema tras el artículo 33 de la LCJIMC (ello, lógicamente, salvo que en un futuro la jurisprudencia incluyese también estos supuestos dentro de los casos "excepcionales"). 
c) Por último, la propia redacción de la norma contenida en el artículo 33.3 de la LCJIMC crea una evidente inseguridad jurídica. Así, se establece que en el caso excepcional de que no se pueda acreditar el derecho extranjero "podrá aplicarse el Derecho español". Parece pues evidente que en tales casos el juez no está imposibilitado para adoptar otras posibles soluciones; esto es, ni siquiera en tales casos calificados como excepcionales tendría la obligación de aplicar el derecho español. Ello, lógicamente, genera inseguridad jurídica para las partes, quienes van a desconocer $a$ priori la solución efectiva que finalmente podrá seguir el juez ante la imposibilidad material y real de acreditar el contenido y vigencia del derecho extranjero.

En definitiva, de lo expuesto cabe concluir que la nueva norma contenida en el artículo 33.3 de la LCJIMC, a pesar de lo que pudiera resultar de una primera y simple lectura, va a resultar de compleja aplicación. No es una norma que recoja en nuestro sistema abiertamente la solución aplicación de la lex fori para los casos de falta de prueba del derecho extranjero, sino que su aplicación va a quedar condicionada al cumplimiento de una serie de circunstancias, en particular, a la consideración por parte del órgano judicial del hecho de encontrarnos ante un supuesto definible como "excepcional", para lo cual habrá que abordar en primer tiempo qué es lo que se va a considerar incluido en tal concepto. De ahí que indicáramos al inicio de este epígrafe III que nos hallamos ante una norma abierta, de gran flexibilidad, que claramente precisará de desarrollo jurisprudencial para ser adecuadamente perfilada. Hasta tanto eso acontezca nos moveremos en el campo de la inseguridad e incertidumbre.

Fecha de recepción: 31 de octubre de 2016

Fecha de aceptación: 26 de abril de 2017

Esta obra está bajo una Licencia Creative Commons

Atribución-NoComercial-SinDerivar 4.0 Internacional, IIJ-UNAM.

Boletín Mexicano de Derecho Comparado, núm. 150, pp. 1351-1394 